\title{
CHANGES TO THE CELL, TISSUE AND ARCHITECTURE LEVELS IN CRANIAL SUTURE SYNOSTOSIS REVEAL A PROBLEM OF TIMING IN BONE DEVELOPMENT
}

\author{
J. Regelsberger ${ }^{1}$, P. Milovanovic ${ }^{2,3}$, T. Schmidt ${ }^{1}$, M. Hahn ${ }^{3}$, E. A. Zimmermann ${ }^{4}$, M. Tsokos ${ }^{5}$, J. Zustin ${ }^{6}$, \\ R. O. Ritchie ${ }^{4}$, M. Amling ${ }^{3}$ and B. Busse ${ }^{3,4, *}$
}

\begin{abstract}
${ }^{1}$ Department of Neurological Surgery, University Medical Centre Hamburg-Eppendorf, Hamburg, Germany ${ }^{2}$ Laboratory for Anthropology, Institute of Anatomy, School of Medicine, University of Belgrade, Belgrade, Serbia ${ }^{3}$ Department of Osteology and Biomechanics, University Medical Centre Hamburg-Eppendorf, Hamburg, Germany

${ }^{4}$ Materials Sciences Division, Lawrence Berkeley National Laboratory, University of California - Berkeley, Berkeley, CA, USA

${ }^{5}$ Institute of Legal Medicine and Forensic Sciences, Charité - University Medicine Berlin, Berlin, Germany ${ }^{6}$ Institute of Pathology, University Medical Centre Hamburg-Eppendorf, Hamburg, Germany
\end{abstract}

\begin{abstract}
Premature fusion of cranial sutures is a common problem with an incidence of 3-5 per 10,000 live births. Despite progress in understanding molecular/genetic factors affecting suture function, the complex process of premature fusion is still poorly understood. In the present study, corresponding excised segments of nine patent and nine prematurely fused sagittal sutures from infants (age range 3-7 months) with a special emphasis on their hierarchical structural configuration were compared. Cell, tissue and architecture characteristics were analysed by transmitted and polarised light microscopy, 2D-histomorphometry, backscattered electron microscopy and energy-dispersive$\mathrm{x}$-ray analyses. Apart from wider sutural gaps, patent sutures showed histologically increased new bone formation compared to reduced new bone formation and osseous edges with a more mature structure in the fused portions of the sutures. This pattern was accompanied by a lower osteocyte lacunar density and a higher number of evenly mineralised osteons, reflecting pronounced lamellar bone characteristics along the prematurely fused sutures. In contrast, increases in osteocyte lacunar number and size accompanied by mineralisation heterogeneity and randomly oriented collagen fibres predominantly signified woven bone characteristics in patent, still growing suture segments. The already established woven-to-lamellar bone transition provides evidence of advanced bone development in synostotic sutures. Since structural and compositional features of prematurely fused sutures did not show signs of pathological/defective ossification processes, this supports the theory of a normal ossification process in suture synostosis - just locally commencing too early. These histomorphological findings may provide the basis for a better understanding of the pathomechanism of craniosynostosis, and for future strategies to predict suture fusion and to determine surgical intervention.
\end{abstract}

Keywords: Human craniosynostosis; sagittal suture; bone structure; bone histomorphometry; biomineralisation.

*Address for correspondence:

Björn Busse

Department of Osteology and Biomechanics (IOBM)

University Medical Center Hamburg-Eppendorf

Lottestr. 59, 22529 Hamburg, Germany
Telephone Number: ++49-40-7410-56687

E-mail: b.busse@uke.uni-hamburg.de

\section{List of abbreviations*}

$\begin{array}{ll}\text { BMP-4 } & \text { bone morphogenetic protein } 4 \\ \text { CBFA1 } & \text { core binding factor alpha 1 } \\ \text { EDXA } & \text { energy dispersive X-ray analysis } \\ \text { FGFR } & \text { fibroblast growth factor receptor } \\ \text { FGF-2 } & \text { basic fibroblast growth factor 2 } \\ \text { IGF-1 } & \text { insulin-like growth factor 1 } \\ \text { (P)MMA } & \text { (poly)methylmethacrylate } \\ \text { qBEI } & \text { quantitative backscattered electron imaging } \\ \text { ROI } & \text { region of interest } \\ \text { SPP-1 } & \text { secreted phosphoprotein 1, osteopontin } \\ \text { TGF-beta } & \text { transforming growth factor beta } \\ \text { TRAP } & \text { tartrate-resistant acid phosphatase } \\ \text { Wt } \% & \text { weight percent }\end{array}$

$\Delta$ width $\mathrm{CaWt} \%$ width of the calcium content distribution

* Histomorphometric indices are listed in Fig. 2.

\section{Introduction}

Craniosynostosis is a common malformation with an estimated incidence of 3-5 per 10,000 live births (Boyadjiev, 2007). The incidence of craniosynostosis has even increased, as recent findings have shown a rise from 2.6 per 10,000 live births in 1997 to 6.4 in 2007 (Kweldam et al., 2010). Moreover, a high incidence of medical problems among children with non-syndromic craniosynostosis (Boyadjiev, 2007) - particularly an increased intracranial pressure (Thompson et al., 1995a; Thompson et al., 1995b; Shimoji and Tomiyama, 2004), ophthalmological problems (Gupta et al., 2003), mental retardation, learning disabilities as well as emotional and behavioural problems (Hunter and Rudd, 1976; Fehlow, 1993; Kapp-Simon et al., 1993; Kapp-Simon, 1998; Magge et al., 2002; Shipster et al., 2003; Lekovic et al., 2004; Van der Vlugt et al., 2009) - has been reported. In particular, major malformations occurred in $22 \%$ of patients with sagittal synostosis (Hunter and Rudd, 1976). 
In contrast to endochondral growth with ossification of a pre-existing cartilaginous matrix, cranial sutures act as intramembranous bone growth sites (Opperman, 2000). New bone is produced at the sutural edges by proliferation of mesenchymal cells and subsequent differentiation into bone-forming osteoblasts (Mathijssen et al., 1999; Moenning et al., 2009). The suture itself remains in a non-ossified stage in which maintenance of growth at the osteogenic fronts requires a balance between proliferation and differentiation of bone forming cells (Opperman, 2000). Disruption of any of these processes can result in premature fusion of calvarial sutures, known as craniosynostosis (Alden et al., 1999).

Premature fusion of cranial sutures is a complex pathomechanism in which alterations in transcription factors, growth factors and their receptors may be the regulating items (Opperman, 2000; Jacob et al., 2007). In suture fusion, type 1 collagen, TGF-beta, FGFR and SPP-1 have been identified to be upregulated in the suture matrix, whereas CBFA1, FGF-2 and IGF-1 become expressed in the adjacent bone borders (Hunenko et al., 2001; Chong et al., 2003; Ignelzi et al., 2003; Eswarakumar et al., 2004; Tholpady et al., 2004; Mooney et al., 2007; Coussens et al., 2008; Moenning et al., 2009; Shen et al., 2009). These processes are most likely occurring in response to external stimuli like the expanding brain (Kokich, 1986; Davis et al., 2009; Oppenheimer et al., 2009). The internal periosteum under the dura mater and the external periosteum may influence bone formation and suture fusion, but the amount and nature of their influences as well as the exact signalling pathway in normal and pathological suture fusion are still unknown (Mooney et al., 2001; Shen et al., 2009; Slater et al., 2009; Wilczak and Ousley, 2009).

Based on studies in animals and clinical observations in humans, suture fusion in isolated synostosis seems to start at one undetermined point and spread along the suture (Cohen, 1993; Opperman, 2000; Regelsberger et al., 2009). This may explain why excellent cosmetic results are achieved by surgical resection in isolated craniosynostosis, if carried out early and before suture fusion is completed. In these cases, surgical resection of the fused suture interrupts the pathological process effectively, assuming that premature fusion is a focal process involving the affected suture and its adjacent bony plates (Cohen, 1993). Although progress has been made to elucidate the events surrounding the cranial suture's fate, predominantly on the molecular and genetic basis, the cause of premature fusion is unknown and much of the suture biology remains poorly understood (David et al., 1982; Kokich, 1986; Slater et al., 2009). In this context, data on bone structure and composition alongside the bony edges of sutures is extremely scarce or contradictory (Enlow, 1982; David et al., 1982; Kokich, 1986; De Pollack et al., 1996; Sherick et al., 2000; Vastardis et al., 2004; Regelsberger et al., 2009). Moreover, it is unknown whether the ossification process in craniosynostosis is pathological itself, or whether it just commences too early. Therefore, in this study we carried out a detailed comparison between patent and synostotic sagittal sutures of infants with special emphasis on the various hierarchical levels. In particular, we analysed the characteristics of the cell, tissue and architecture levels in control and craniosynostosis cases to provide new insights into the composition and morphology of both normal and synostotic sutures.

\section{Materials and Methods}

The study group was comprised of nine infants (age range: 3-7 months, mean: 4.4 months) with isolated i.e., nonsyndromic synostosis of the sagittal suture (Fig. 1a). The diagnostic procedure was based on clinical examination (characteristic skull deformity) and confirmed by near-field high-frequency ultrasound as previously suggested by Regelsberger et al. (2006). In the cases with prematurely fused sagittal sutures, the complete sagittal suture with the adjacent osseous tissue was resected during surgery (Fig. 1b,c). For the control group, corresponding patent sagittal suture samples were taken from nine infants of an equivalent age (age range: 3-7 months, mean: 4.7 months). The patent segments of the sagittal sutures were excised in the control cases during autopsy. The circumstances leading to their deaths were sudden infant death syndrome or other causes not related to central nervous system diseases or cranial vault pathological entities. Contact radiography of the excised suture segments demonstrated the presence or absence of synostosis (Fig. 1c,d). MicroCT ( $\mu$ CT 40, Scanco Medical, Brüttisellen, Switzerland) scans of the specimens were taken perpendicular to the suture to illustrate the orientation that was used for the subsequent structural and compositional analyses (Fig. 1e,f). Informed written parental consent was obtained prior to our investigations. Furthermore, this study was in accordance with the local ethics regulations (Hamburgisches Gesetz- und Verordnungsblatt, Gesetz zur Regelung von klinischen, rechtsmedizinischen und anatomischen Sektionen (Sektionsgesetz 9-2-2000 §2)).

\section{Undecalcified preparation of the specimens}

A part of each resected sagittal suture (approximately $2 \mathrm{~cm} \times 6 \mathrm{~cm}$, red rectangle, Fig. 1a,b) was prepared in order to perform histological and compositional analyses. Specifically, two cores (approximate dimensions: $2 \mathrm{x}$ $0.5 \mathrm{~cm}$ ) per suture were excised perpendicular to the suture (in positions indicated by the dashed lines in Fig. 1c,d) to assess the structural and cellular indices of the sutures' bony edges in both the synostotic and the control samples. All samples were embedded in polymethylmethacrylate (PMMA) as described previously to allow artefact-free undecalcified preparation of bone tissue while preserving the bone matrix and cellular features (Hahn et al., 1991). In particular, prior to embedding, the samples were first fixed in $4 \%$ phosphate-buffered formaldehyde and then dehydrated in an ascending ethanol series (70 \%, $90 \%$, $100 \%$ ethanol). Afterwards, the bone specimens were embedded without decalcification in MMA (Merck, Darmstadt, Germany). The destabilised MMA (Merck \#8.00590) was augmented with LPG (nonylphenol, SigmaAldrich, St. Louis, MO, USA, \#74430) as softener and benzoyl peroxide (Merck \#801641) and N,N dimethyl-ptoluidine (DMPT) (Merck \#822040) as initiator/catalyst. The polymerisation process was performed at a temperature 
Fig. 1. (a) Computed tomography (CT) reconstructions of the skull of two infants with sagittal suture synostosis (side view: age 13 weeks, and top view: age 11 weeks) showing a premature closure of the sagittal suture, while the coronal suture (white arrows) and lambdoid suture (black arrows) show patency. In the course of surgery, the whole sagittal suture was resected with the adjacent osseous tissue (dotted red lines); (b) A part of the resected fused suture of approximately $6 \times 2 \mathrm{~cm}$ (red rectangle) was obtained for this study. (c) Contact specimen x-ray (cranio-caudal projection) of the excised fused suture segment (age 13 weeks) showing dense mineralised bone parallel to the barely existing suture gap; (d) Contact specimen x-ray (cranio-caudal projection of the excised patent suture from a control case aged 12 weeks). The sutural gap can be observed as the radiolucent area between the mineralised bones of the cranium. The dashed lines in (c) and (d) mark the two adjacent regions used for the subsequent preparation of undecalcified histological blocks perpendicular to the suture; (e) Micro-CT scans of the sections perpendicular to a clinically fused suture showing a narrow gap, while in (f) a widely open suture gap is visible in a control case.

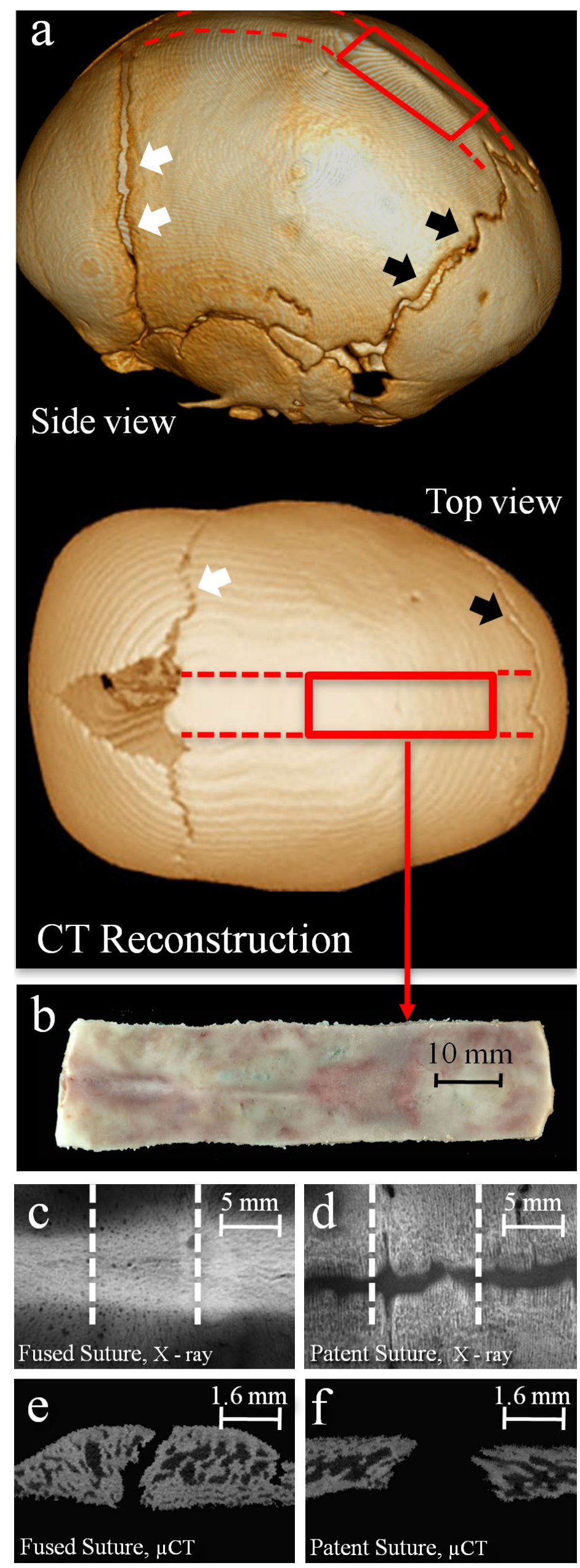




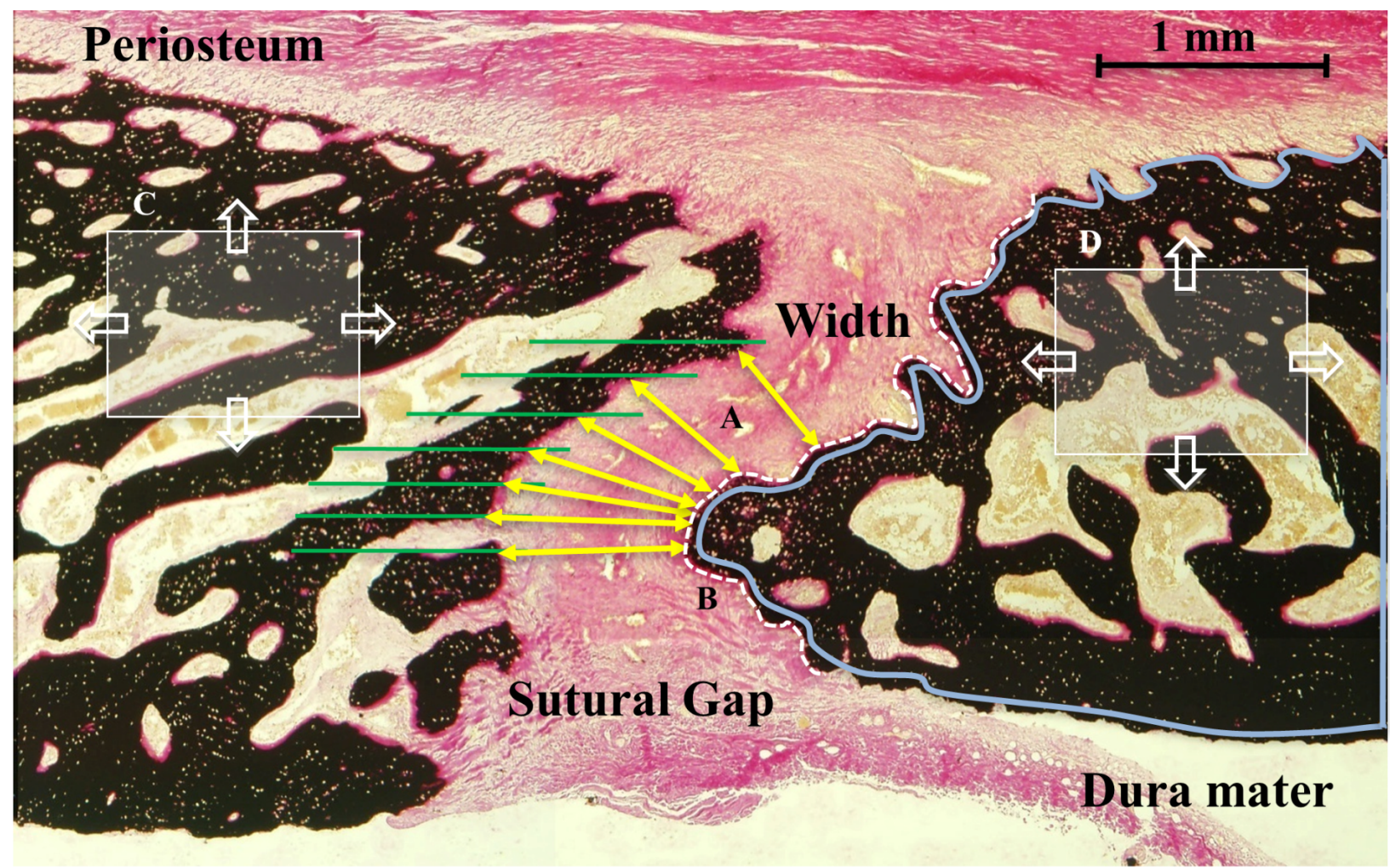

\begin{tabular}{|c|c|c|c|c|}
\hline & $\mathrm{ROI}$ & 2D Histomorphometry & Description & Units \\
\hline \multirow{7}{*}{ 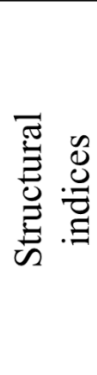 } & $\mathrm{A}$ & Gap Width & mean width of the sagittal suture & $\mathrm{mm}$ \\
\hline & $\mathrm{B}$ & Fb.T.Pm/B.Pm & $\begin{array}{l}\text { sutural bone perimeter covered by fibrous } \\
\text { tissue per sutural bone perimeter }\end{array}$ & $\%$ \\
\hline & $\mathrm{C}, \mathrm{D}$ & B.Ar/T.Ar & bone area per tissue area & $\%$ \\
\hline & $\mathrm{C}, \mathrm{D}$ & O.Ar/B.Ar & osteoid area per bone area & $\%$ \\
\hline & $\mathrm{C}, \mathrm{D}$ & O.Pm/B.Pm & osteoid perimeter per bone perimeter & $\%$ \\
\hline & $\mathrm{C}, \mathrm{D}$ & O.Th & osteoid thickness & $\mu \mathrm{m}$ \\
\hline & $\mathrm{C}, \mathrm{D}$ & N.On/B.Ar & number of osteon profiles per bone area & $\# / \mathrm{mm}^{2}$ \\
\hline \multirow{4}{*}{ 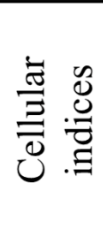 } & $\mathrm{C}, \mathrm{D}$ & N.Ot.Lc/B.Ar & number of osteocyte lacunae per bone area & $\# / \mathrm{mm}^{2}$ \\
\hline & $\mathrm{C}, \mathrm{D}$ & Ot.Lc.Ar & mean osteocyte lacunar area & $\mu \mathrm{m}^{2}$ \\
\hline & $\mathrm{C}, \mathrm{D}$ & N.Oc/T.Ar & number of osteoclasts per tissue area & $\# / \mathrm{mm}^{2}$ \\
\hline & $\mathrm{C}, \mathrm{D}$ & Ob.Pm/B.Pm & $\begin{array}{c}\text { bone perimeter covered by osteoblasts per } \\
\text { bone perimeter }\end{array}$ & $\%$ \\
\hline
\end{tabular}

Fig. 2. Schematic illustrating the histomorphometric measurements used to assess the cell and tissue characteristics of the sutures (Patent or unfused sagittal suture, von Kossa/van Gieson stain: mineralised bone tissue = black, soft tissue and osteoid = reddish tones). The gap width was measured in region of interest (ROI A) by means of a manually positioned grid (green gridlines) where the shortest distances (yellow arrows) from the gridlines to the opposed mineralised edge were randomly collected and averaged as the mean gap width. Note that 7 gridlines are shown here for illustration, while the true number of gridlines used for analysis depended on the size of suture margins and were positioned from inner periosteum (near the dura mater) to the outer periosteum edge of the suture. The sutural bone perimeter covered by fibrous tissue per bone perimeter (Fb.T.Pm/B.Pm; ROI B) represents a percentage of the sutural bone perimeter (shown by white dashed line) that is covered by dense irregular connective tissue. Further structural and cellular indices were assessed within the edges of the bony plates on each side of the suture (ROIs C and D) up to $3 \mathrm{~mm}$ lateral from the mineralised suture front, within the area indicated by the blue outline (for simplicity shown only on the right side). 2D histomorphometry was carried out in measuring fields that were moved (white rectangle with arrows) within the outlined area. Of note, the blue outline is drawn a little bit separated from the white dashed line for the sake of visibility, but the white dashed line actually represents the sutural bone perimeter. 
of $4{ }^{\circ} \mathrm{C}$. After the completion of polymerisation, the embedded suture samples had a cylindrical block shape, which is appropriate for microtome cutting. Eight crosssections per PMMA-block (sixteen cross-sections per individual) with a thickness of approximately $4 \mu \mathrm{m}$ each were cut with a rotation microtome (Cut $4060 \mathrm{E}$, microTec, Walldorf, Germany) and stained with von Kossa/ van Gieson, toluidine blue, Goldner's modified Massontrichrome, and tartrate-resistant acid phosphatase (TRAP). Four microscope slides per block were used for spreading 8 microtome cross sections.

Von Kossa with van Gieson counterstain (acidic fuchsin) was used to differentiate osteoid/collagen (red) from mineralised bone (black), while the toluidine blue and Goldner's modified Masson-trichrome stains were applied to examine the bone cell morphology, resorption cavities, mineralisation fronts and bone remodelling units (Vedi and Compston, 2003). In order to visualise osteoclast numbers, we applied Tartrate resistant acid phosphatase staining to the undecalcified bone sections (Vedi and Compston, 2003).

\section{Static 2D-histomorphometry and qualitative analysis}

Histologic sections stained by means of the von Kossa/van Gieson, Goldner's modified Masson-trichrome and toluidine blue protocols enabled static bone histomorphometry (Osteo, BioQuant Image Analysis Corp., Nashville, TN, USA; and Osteomeasure, OsteoMetrics, Decatur, GA, USA) in accordance with ASBMR (American Society of Bone and Mineral Research; www.asbmr.org) guidelines (Parfitt et al., 1987). Fig. 2 shows an example specimen of a von Kossa/van Gieson stained sagittal suture and illustrates the locations in the sutures where structural and cellular indices were assessed. The mean width of the sagittal suture (gap width, mm) was assessed by means of a manually positioned grid where the shortest distances from the gridlines to the opposed mineralised edge were determined by an interactive automatic procedure and averaged (for further explanation, see Fig. 2). The sutural bone perimeter covered by fibrous tissue per bone perimeter (Fb.T.Pm/B.Pm, \%) was determined as the ratio between the perimeter of the sutural bony edges that is covered by the fibrous tissue (dense irregular connective tissue) and total perimeter of the sutural bone edges (see Fig. 2). Furthermore, structural indices were assessed at both the left and right osseous edges of the sagittal suture in the $3 \mathrm{~mm}$-wide zones lateral to the mineralised suture front. The total area of the tissue profile used for quantitative evaluation was 7-9 $\mathrm{mm}^{2}$ per suture edge, i.e., 14-18 $\mathrm{mm}^{2}$ per section. Measuring fields covered this complete area of interest, while size and number of fields depended on the microscopic magnification (which depends on the evaluated parameter). The following structural indices were measured in these regions: bone area per tissue area (B.Ar/T.Ar, \%), osteoid area per bone area (O.Ar/B. Ar, \%), osteoid perimeter per bone perimeter (O.Pm/B. $\mathrm{Pm}, \%)$, osteoid thickness (O.Th, $\mu \mathrm{m})$ and number of osteon profiles per bone area (N.On/B.Ar, $\# / \mathrm{mm}^{2}$ ). The Osteomeasure system was used to automatically calculate osteoid thickness, which requires manual marking of the inner and outer boundary of osteoid. According to the underlying 2D histomorphometry approach, only osteon profiles that had been cut transversally or obliquely were counted. Considering the guidelines from Parfitt et al. (1987), "bone area" refers to both mineralised and osteoid areas. The following cellular indices were evaluated: number of osteocyte lacunae per bone area (N.Ot.Lc/B. $\mathrm{Ar}, \# / \mathrm{mm}^{2}$ ), mean osteocyte lacunar area (Ot.Lc.Ar, $\mu \mathrm{m}^{2}$ ), number of osteoclasts per tissue area (N.Oc/T.Ar, $\# / \mathrm{mm}^{2}$ ) and bone perimeter covered with osteoblasts per bone perimeter (Ob.Pm/B.Pm, \%). These parameters provided individual classification of the bone status in the adjacent bony plates of patent and fused sutures (Fig. 2 ). The term "osteoblasts" as used in this study refers to surface osteoblasts, unless specified otherwise. Image analysis segmentation included the selection of a threshold corresponding to the mineralised bone plus osteoid for the Bioquant software (for B.Ar/T.Ar), while other parameters were thresholded manually to obtain the corresponding ratios via the Osteomeasure system. For quantification of osteoblasts and osteoclasts, toludine blue- and TRAPstained sections were used, while Goldner staining was used to determine Fb.T.Pm/B.Pm.

In addition to the quantitative analysis, further qualitative analyses were carried out to investigate whether the ossification bears any signs of pathological conditions (i.e., peculiar characteristics of: (a) cellular presence, appearance and number; (b) architecture/arrangement of the bone tissue; (c) presence/absence of resorption cavities; (d) relative thickness of bone compartments; (e) presence/ absence of mosaic organisation, mineralisation degree and mineralisation patterns).

\section{Polarised light microscopy}

In histological sections, the orientation of the collagen fibrils in the bone tissue can be illustrated under linearly polarised light. Collagen fibrils or bundles of fibrils, which are cut longitudinally and run parallel to the polariser or analyser plane, appear bright on the dark background, while cross-sectioned fibrils or fibres appear dark. The application of linearly polarised light on histological sections ensured a qualitative assessment of the osseous maturation, i.e., distinction between woven and lamellar bone, within the segments of the infants' sutures.

\section{Energy dispersive $x$-ray microanalysis}

The plastic-embedded block specimens were polished at the surface and carbon coated for scanning electron microscopy and non-destructive microanalysis with EDXA (energy dispersive x-ray analysis; EDAX, DX-4, Mahwah, NJ, USA) allowing spatial investigation of the elemental concentrations (Busse et al., 2010a; Busse et al., 2010b). It is necessary to note that depending on the electron beam settings, damage to the surface of the polished block may occur during the EDXA (Bloebaum et al., 2005). To analyse the elemental composition of the sutural soft tissue, EDXA was performed in three regions of interest (ROI): the connective tissue in the centre of the suture gap, and in the soft tissue adjacent to each of the sutural margins where initial ossification is expected. These ROIs were $0.01 \mathrm{~mm}^{2}$ in size, each. Elemental peaks reflecting pronounced calcium $(\mathrm{Ca})$, phosphorus $(\mathrm{P})$, oxygen $(\mathrm{O})$ 
and sulphur $(\mathrm{S})$ contents in the suture were evaluated in weight percent (Wt-\%) by means of EDX-ZAF software provided by the manufacturer (EDAX, DX-4). Hence, EDXA quantifies the relative contribution of each of the detected elements (within the ROI) to $100 \%$.

\section{Bone mineral density distribution analysis}

The backscattered electron (BSE) mode of scanning electron microscopy was used to assess the degree of mineralisation in the bony plates lateral to the sagittal suture over an area similar to that used for the histomorphometric assessment. The application is based on previous work that established quantitative backscattered electron imaging (qBEI) (Roschger et al., 1995; Roschger et al., 1998). The scanning electron microscope (LEO 435 VP, LEO Electron Microscopy Ltd., Cambridge, England) was operated at $15 \mathrm{kV}$ and $665 \mathrm{pA}$ at a constant working distance (BSE Detector, Type 202, K.E. Developments Ltd., Cambridge, England) in line with our previous studies (Busse et al., 2009; Busse et al., 2010a, 2010b). The pixel size was $3 \mu \mathrm{m}$ according to the recommendations of Roschger et al. (Roschger et al., 2008). Synthetic hydroxyapatite samples were used to create a calibration curve. These hydroxyapatite samples (DOT Medical Solutions, Rostock, Germany) contained different $\mathrm{Ca} / \mathrm{P}$ ratios, which were determined using energy dispersive $\mathrm{X}$-ray analysis (DX-4, EDAX) and qBEI. A highly linear relationship
( $r=0.98)$ between the grey values of the backscattered signal intensities and the calcium content $(\mathrm{CaWt} \%)$ in each sample has also been reported by other authors (Skedros et al., 1993; Roschger et al., 1995; Roschger et al., 1998), which enables calibration of the method. The generated mineralisation profiles (grey value histograms) for each specimen represent the mean calcium weight percent (mean $\mathrm{CaWt} \%$ ) and indicate the average calcium content in the mineralised bone tissue area, while the width calcium value ( $\Delta$ width $\mathrm{CaWt} \%$ ) reflects the homogeneity of mineralisation, i.e., the width of the calcium content distribution in the given bone area.

\section{Statistical Analysis}

The data were subjected to the Shapiro-Wilk test to define the distribution. In the case of normally distributed data, a $t$-test was used for comparisons. Non-parametric data were analysed by the paired Wilcoxon rank sum test. $P$-values of $p \leq 0.05$ were considered to be significant.

\section{Results}

\section{Static 2-D histomorphometry}

In line with qualitative contact $x$-ray analyses, the patent segments demonstrated a wide-open sutural gap (Fig. 3a; Table 1) in contrast to the very narrow gaps in prematurely

Table 1: Histomorphometric assessment of structural indices.

\begin{tabular}{|c|c|c|c|c|c|}
\hline & 2D Histomorphometry & Localisation & Patent Suture & Fused Suture & $p$ \\
\hline \multirow{7}{*}{ 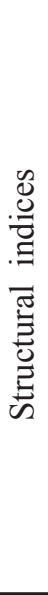 } & $\begin{array}{l}\text { Gap Width } \\
\text { [mm] }\end{array}$ & sutural gap & $1.23 \pm 0.32$ & $0.48 \pm 0.14$ & $\leq 0.0005$ \\
\hline & $\begin{array}{c}\text { Fb.T.Pm/B.Pm } \\
{[\%]} \\
\end{array}$ & sutural gap & $86.71 \pm 9.1$ & $13.29 \pm 16.69$ & $\leq 0.0005$ \\
\hline & $\begin{array}{c}\text { B.Ar/T.Ar } \\
{[\%]}\end{array}$ & sutural edges & $61.88 \pm 9.72$ & $57.92 \pm 7.81$ & N.S. \\
\hline & $\begin{array}{c}\text { O.Ar/B.Ar } \\
{[\%]} \\
\end{array}$ & sutural edges & $4.62 \pm 0.59$ & $3.58 \pm 0.76$ & $\leq 0.05$ \\
\hline & $\begin{array}{c}\text { O.Pm/B.Pm } \\
{[\%]}\end{array}$ & sutural edges & $35.91 \pm 4.45$ & $34.79 \pm 4.48$ & N.S. \\
\hline & $\begin{array}{l}\text { O.Th } \\
{[\mu \mathrm{m}]}\end{array}$ & sutural edges & $8.23 \pm 0.66$ & $7.33 \pm 0.58$ & $\leq 0.05$ \\
\hline & $\begin{array}{c}\text { N.On/B.Ar } \\
{\left[\# / \mathrm{mm}^{2}\right]}\end{array}$ & sutural edges & $2.87 \pm 1.9$ & $8.10 \pm 1.27$ & $\leq 0.005$ \\
\hline
\end{tabular}

N.S.= not significant

For abbreviations, see Fig. 2

Table 2: Histomorphometric assessment of cellular indices

\begin{tabular}{|c|c|c|c|c|c|}
\hline & 2D Histomorphometry & Localisation & Patent Suture & Fused Suture & $p$ \\
\hline \multirow{2}{*}{\begin{tabular}{c}
$\qquad \begin{array}{c}\text { Ob.Pm/B.Pm } \\
{[\%]}\end{array}$ \\
\cline { 2 - 6 }
\end{tabular}} & $\begin{array}{c}\text { N.Ot.Lc/B.Ar } \\
{\left[\# / \mathrm{mm}^{2}\right]}\end{array}$ & sutural edges & $40.29 \pm 15.29$ & $24.53 \pm 2.68$ & $\leq 0.05$ \\
\cline { 2 - 6 } & $\begin{array}{c}\text { Ot.Lc.Ar } \\
{\left[\mu \mathrm{m}^{2}\right]}\end{array}$ & sutural edges & $445.85 \pm 46.16$ & $251.28 \pm 79.84$ & $\leq 0.0005$ \\
\cline { 2 - 6 } & $\begin{array}{c}\text { N.Oc/T.Ar } \\
{\left[\# / \mathrm{mm}^{2}\right]}\end{array}$ & sutural edges & $8.5 \pm 1.66$ & $16.4 \pm 2.24$ & $\leq 0.005$ \\
\hline
\end{tabular}

For abbreviations, see Fig. 2 


\section{Patent Suture}
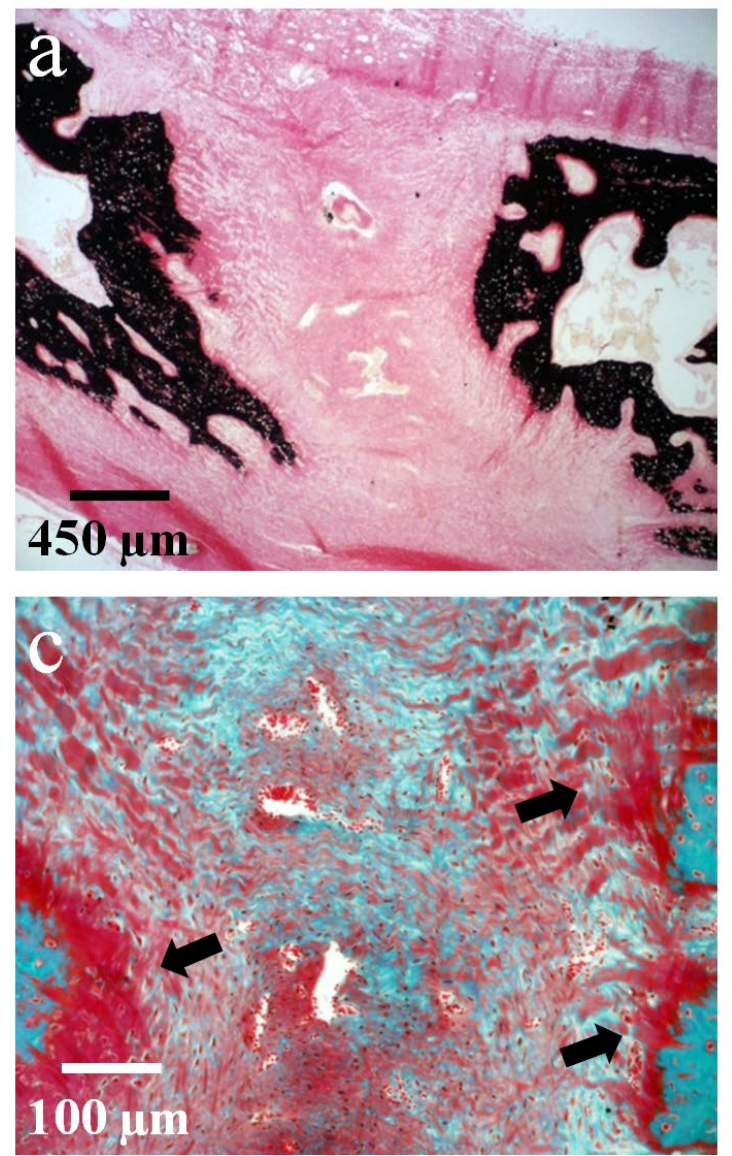

\section{Fused Suture}
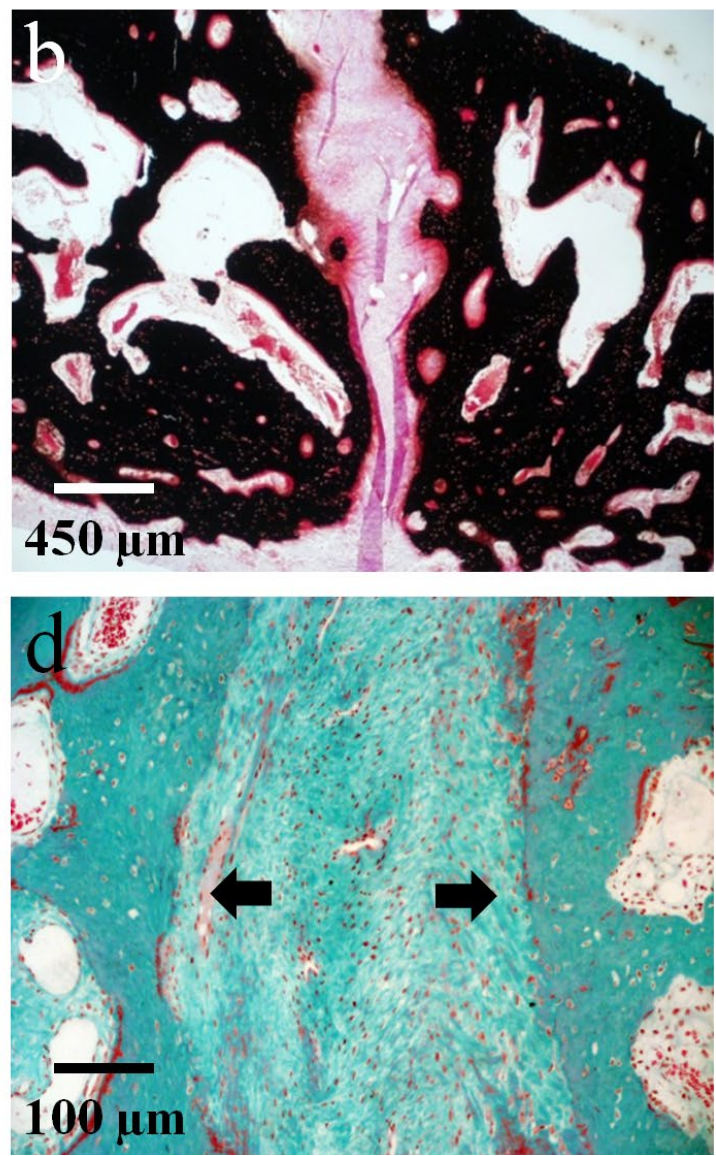

Fig. 3. Undecalcified histological sections of patent segments from sagittal sutures (a) showed wide-open fibrous tissue gaps in comparison to (b) the narrow suture gaps in clinically fused segments (mineralised bone tissue $=$ black, soft tissue = red; von Kossa/van Giesson); (c) Patent sutures indicated an increased amount of collagen fibres (stained in red, black arrows); the fibres frequently were oriented at a roughly $45^{\circ}$ angle to the mineralised fronts of the sutural bony edges (stained in green, Goldner's trichrome stain), but some fibres did show other oblique angles; (d) The specimens from the cases with clinically fused sutures showed significantly narrower suture gaps with minor amounts of frayed dense irregular connective tissue between smooth outlines of the adjacent mineralised bone (black arrows; Goldner's trichrome stain).
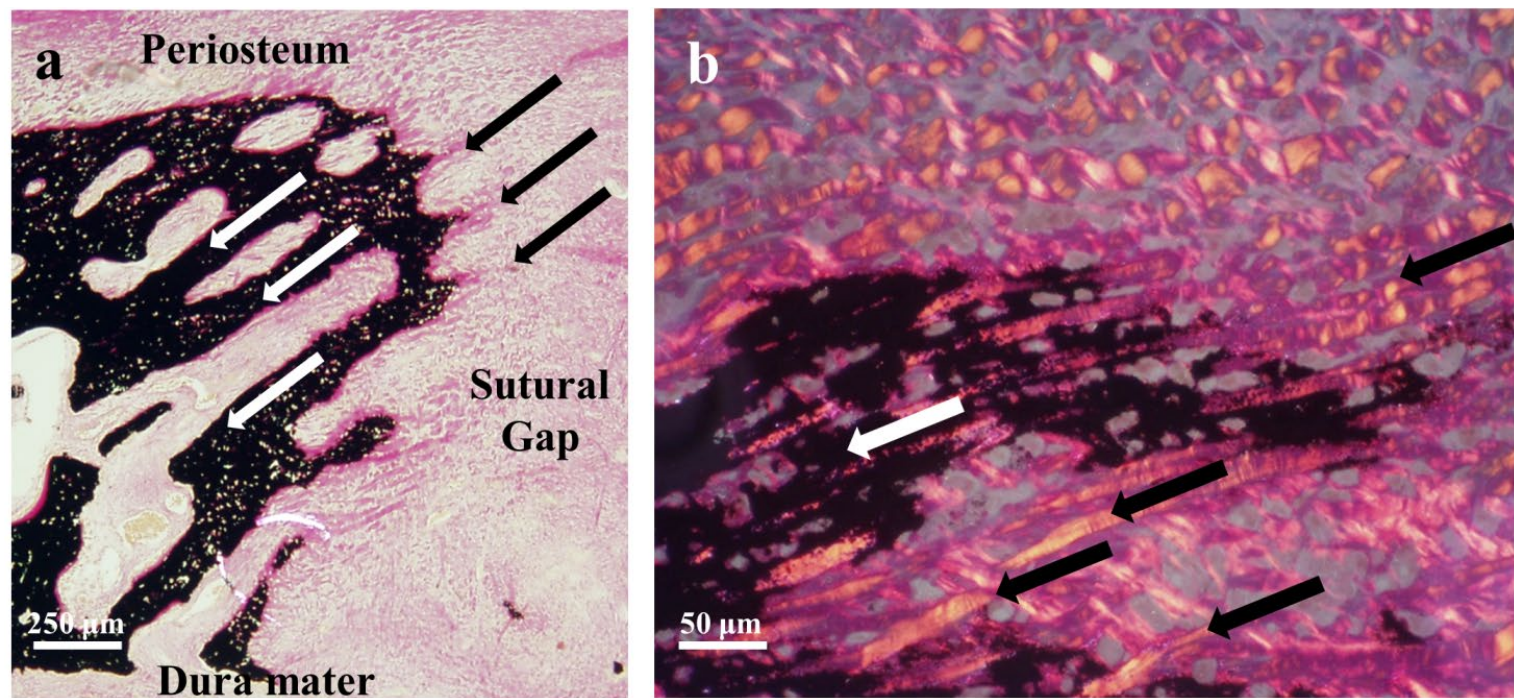

Fig. 4. Pattern of trabecular orientation in patent sutures: (a) bright field low-power image (von Kossa/van Gieson); (b) polarised light high-power image. Mineralised bone trabeculae (white arrows) seem to follow the orientation of pre-existing mesenchymal tissue and collagen fibres (black arrows). 

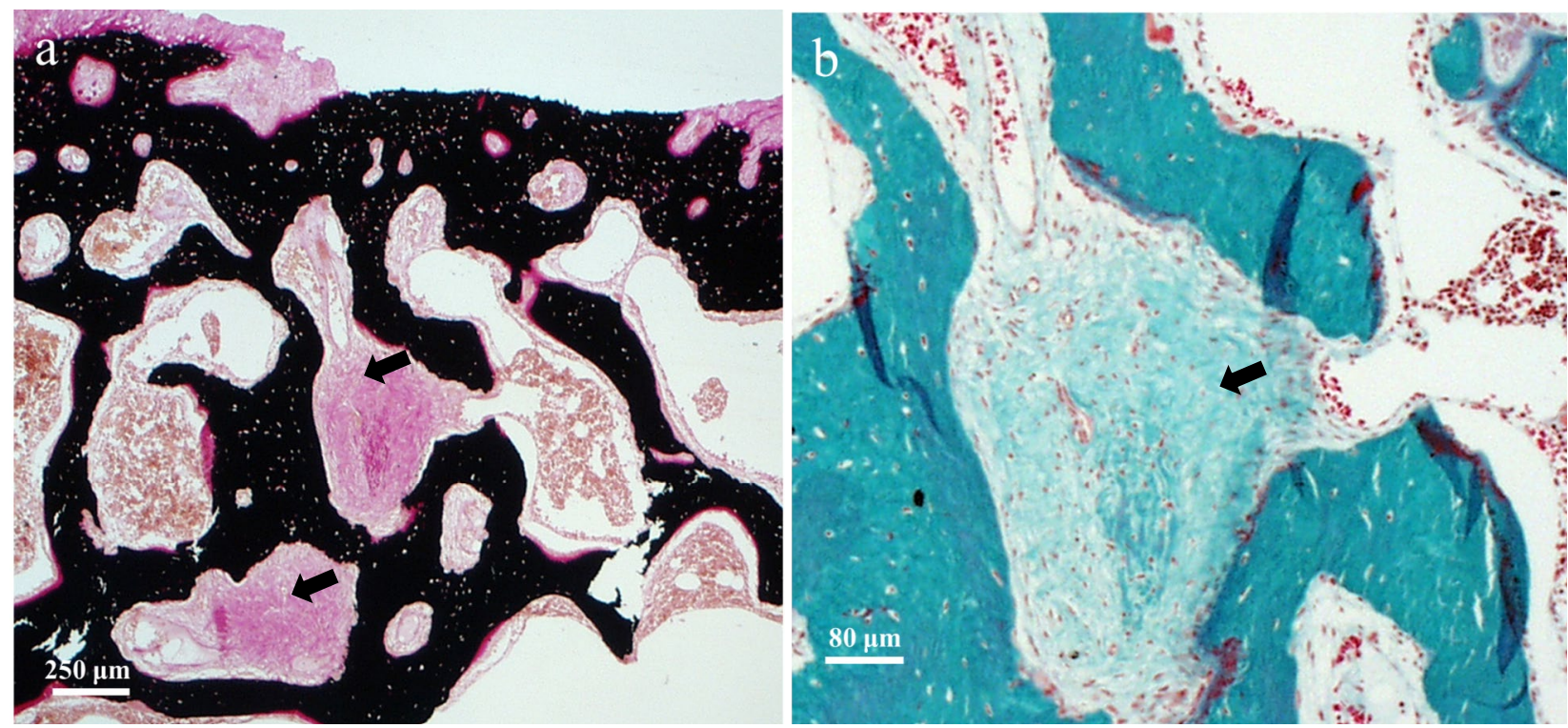

Fig. 5. (a) A Von Kossa/Van Gieson stained specimen from one of two patients with complete fusion of the sagittal suture (both 4.5 months old), showing bridged sutural margins with two small islands of remnant sutural connective tissue (arrow) in the centre of the former suture gap; (b) A high power Goldner's trichrome staining showing the fibrous remnants (arrow) of the former suture gap, which is bridged by mineralised bone (see (a)).

fused sutures (Fig. 3b; Table 1). The ratio of bone area per tissue area was unchanged in patent segments compared to fused segments (Table 1). In contrast, the sutural edges of patent segments demonstrated an increased amount of frayed dense irregular connective tissue (Fig. 3c; Table 1), compared to already fused sutures (Fig. 3d; Table 1). The pronounced colour differentiation between the green-stained mesenchymal tissue and the red-stained fibres was a specific feature of patent sutures in Goldner's modified Masson-trichrome staining (Fig. 3c). The pattern of collagen fibre orientation and trabecular alignment is shown in Fig. 4. In two infants with craniosynostosis, the bony fusion process was almost complete indicating true synostosis (Fig. 5).

Osseous suture margins of patent segments showed an increased presence of prominent osteoblastic cells with a regular cuboidal shape (Fig. 6a; bone perimeter covered with osteoblasts per bone perimeter: Table 2), whereas the fused segments demonstrated a smaller osteoblast population (Fig. 6b, Table 2). These osteoblasts in fused cases were rather flat-shaped, which is indicative of a quiescent phase and lower bone-forming ability (Fig. 6b). Accordingly, the fused sutures showed a reduced osteoid area per bone area, as well as a decreased osteoid thickness (Fig. 6c,d; Table 1). An increased number of osteon profiles per bone area (N.On/B.Ar, $\# / \mathrm{mm}^{2}$ ) was measured in fused segments (Fig. 6d; Table 1), in contrast to lower numbers of osteons in patent sutures (Fig. 6c; Table 1). In contrast to the patent sutures, pronounced internal osteoclastic resorption in the bone plates of prematurely fused sutures was suggested by the appearance of numerous osteoclasts (Fig. 6b; Table 2; also evidenced by their TRAP positivity - Fig. 6e,f) in Howship's lacunae.

In patent segments, higher numbers of osteocyte lacunae (N.Ot.Lc/B.Ar, \#/mm²) with no specific alignment were observed (Fig. 6g; Table 2), whereas in fused segments, the osteocyte lacunar density was significantly lower (Fig. 6h; Table 2). The average osteocyte lacunar size (Ot.Lc.Ar, $\mu \mathrm{m}^{2}$ ) decreased significantly in fused sutures in comparison to the patent ones (Fig. 6g,h; Table 2).

Fig. 6 (on next page). (a) In patent sutures, there were seams of osteoid-secreting regular cube-shaped osteoblasts (OBL) that were forming osteons infrequently within predominantly woven bone area (osteoid = light blue, mineralised bone = blue; toluidine blue); (b) In contrast, bone of the fused sutures showed lower osteoblast numbers (OBL) in contrast to numerous osteoclasts (OCL) in Howship's lacunae on the endosteal side of the bone bordering the remaining sutural gap, indicating a more advanced stage of bone restructuring (toluidine blue); (c) The amount of osteoid area (black arrows) per bone area showed increased values accompanied by low numbers of osteon profiles per bone area in patent sutures (osteoid = red, mineralised bone = green; Goldner's trichrome stain); (d) In contrast, fused sutures revealed decreased areas of osteoid (black arrows) per bone area accompanied by elevated numbers of osteon profiles that interrupt remnant cellular woven bone areas (WB) (Goldner's trichrome stain). (e). In patent sutures, a lower number of osteoclasts (OCL) per bone area in comparison to fused sutures (f) was further confirmed by the red TRAP-staining; (g) Bony edges of patent sutures display more numerous irregularly sized osteocyte lacunae indicating the woven bone, along with inserting collagen fibers from the suture (mineralised bone tissue $=$ black, soft tissue and osteoid = reddish tones; von Kossa/van Gieson); (h) In contrast, osteocyte lacunae in fused segments were smaller and less densely arranged (von Kossa/van Gieson). 


\section{Patent Suture}
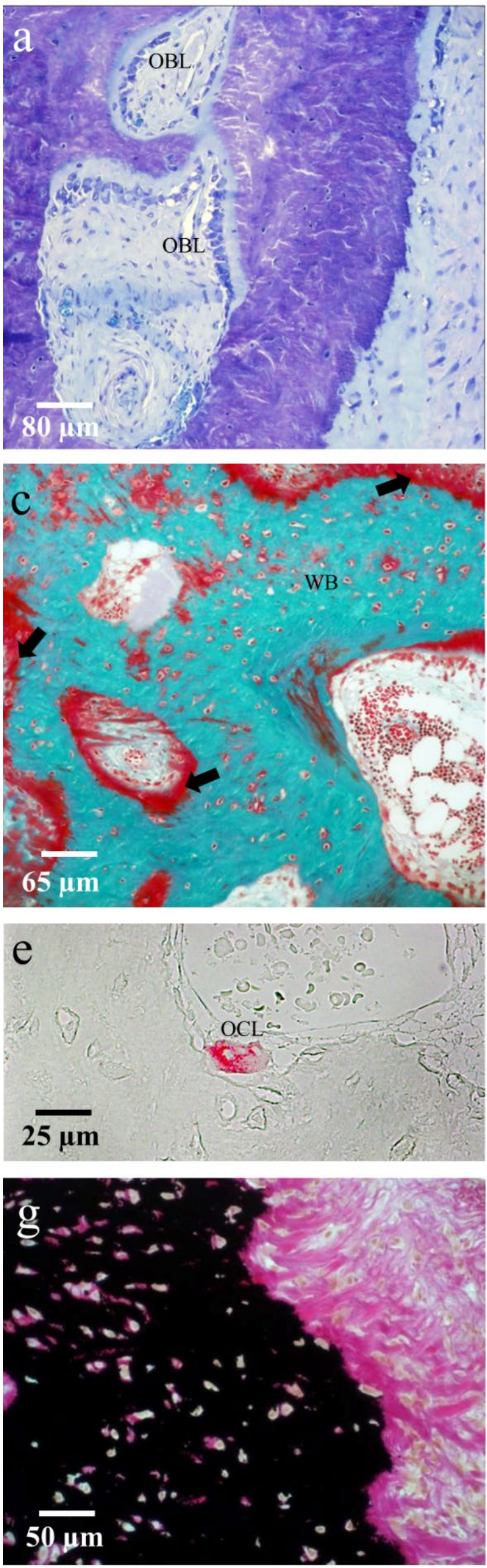

Fused Suture
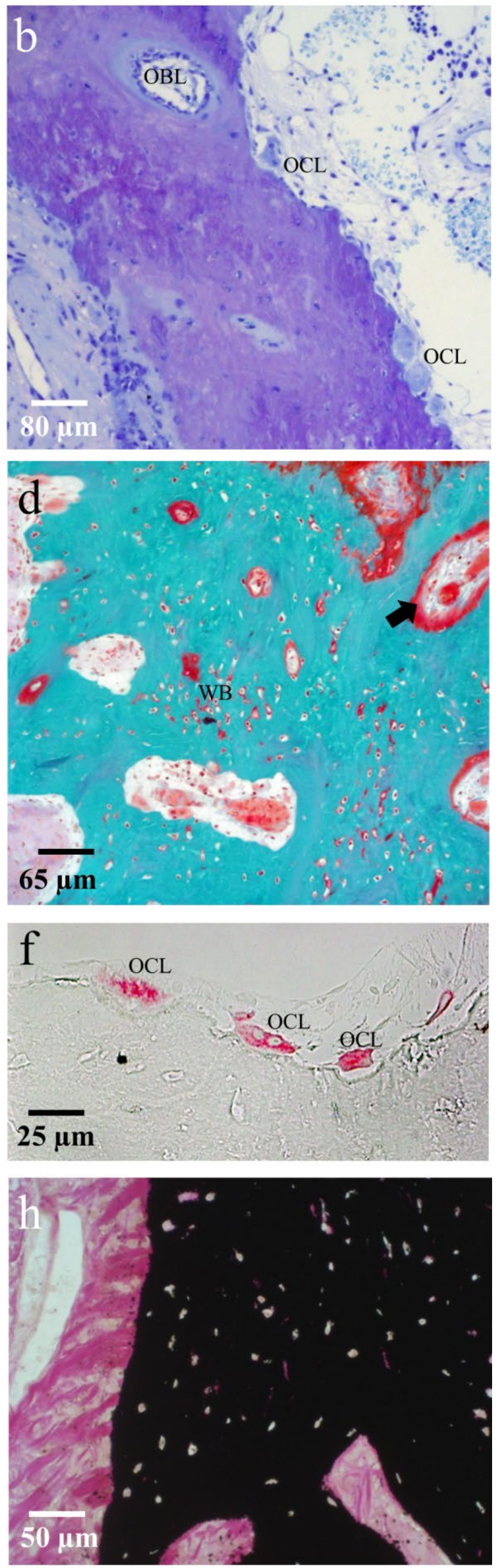
Patent Suture

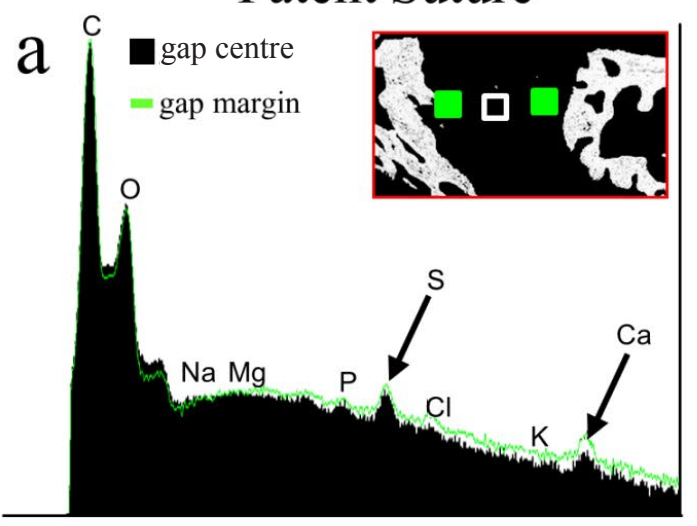

Fused Suture

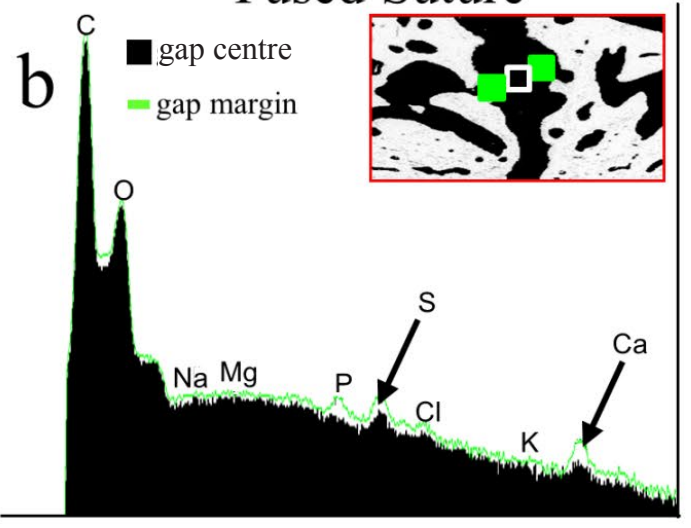

Patent Suture

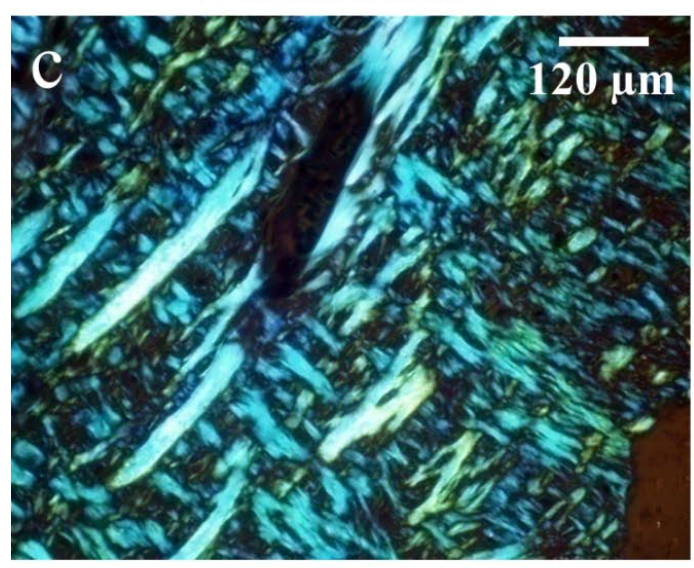

Fused Suture

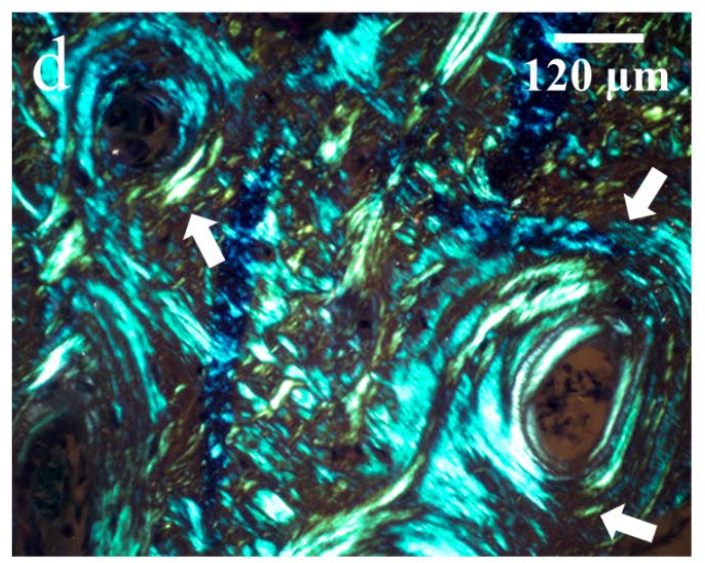

Patent Suture

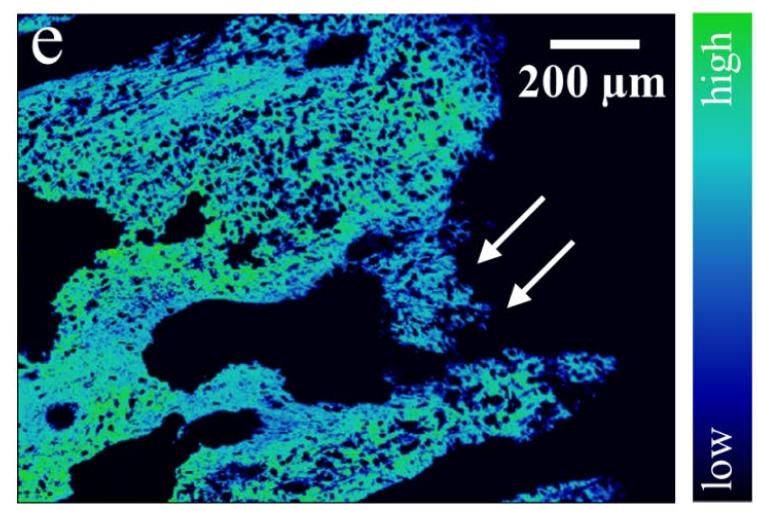

Fused Suture

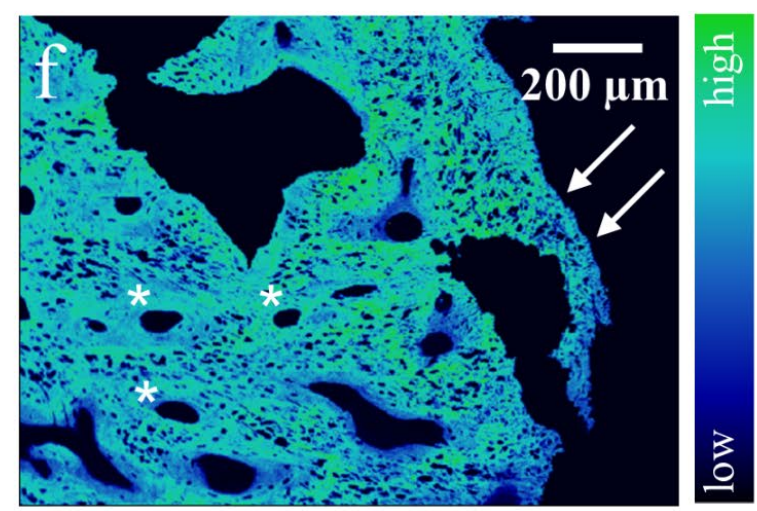

Patent

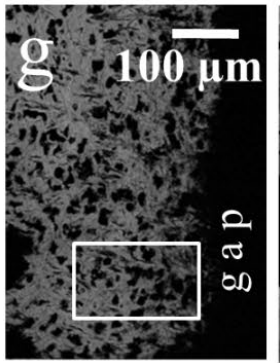

Fused

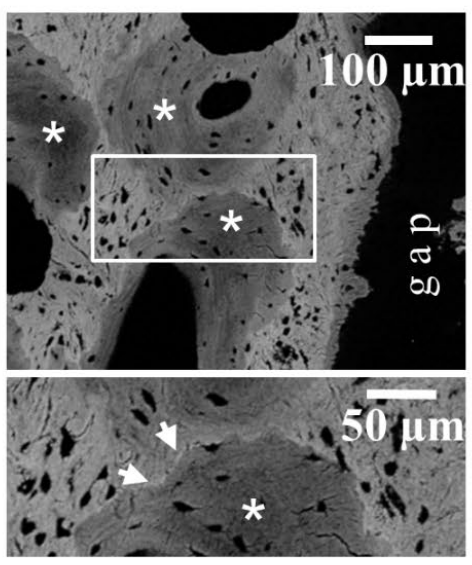

Mean Ca

Width Ca

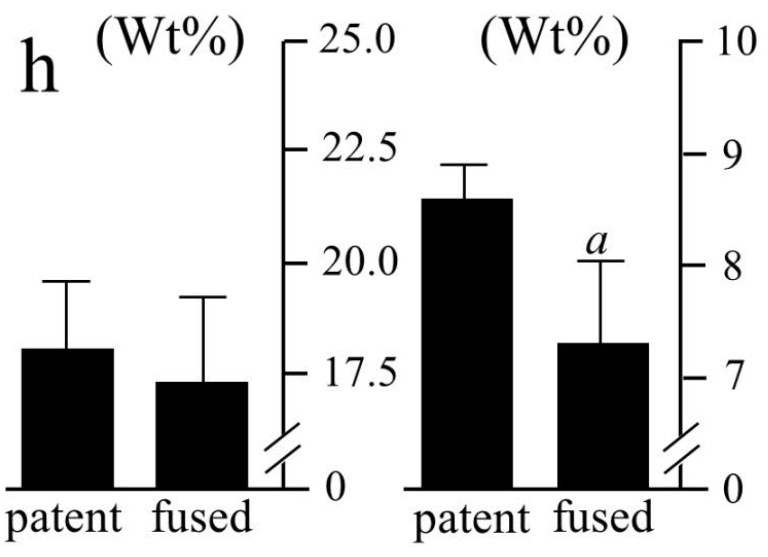


Fig. 7 (on previous page). Energy dispersive $x$-ray analysis of the suture centre and soft tissue near the suture margins in the patent sutures (a) and fused sutures (b). In both the patent and fused sutures, significantly increased proportions of calcium $(\mathrm{Ca})$ and sulphur $(\mathrm{S})$ were found near the edges of the suture gap in comparison to the suture centres, probably indicating an increased amount of calcium available for mineralisation and sulphated glycosaminoglycans triggering this process; (c) Under polarised light, patent sutures showed evidence of woven bone formation, while in fused sutures (d) lamellar organisation (white arrows) of the collagen fibrils was evident where focal existence of these matured osteonal entities interrupts the remaining woven bone characteristics (toluidine blue, polarised light); (e) Bone mineral density distribution analyses revealed predominantly inhomogeneous, mineralised woven bone and a frayed, low-mineralised sutural surface (arrows) in patent sutures, while bony plates alongside the fused segments (f) revealed frequently evenly mineralised secondary osteons (asterisks) and smooth mineralised periosteal outlines (arrows) (bluish pixels = low mineral content, greenish pixels = higher mineral content, pseudocoloured quantitative backscattered image); (g) Details from backscattered electron images of the patent (left image) and fused suture (right image): a frayed sutural outline and woven bone characteristics in the patent sutural edge vs. frequent osteonal features (asterisks) with thin cement lines (white arrows) in the clinically fused sutural margins; (h) The overall mean calcium weight percent (mean $\mathrm{Ca}, \mathrm{Wt} \%$ ) as a measure of the average calcium content in the detected bone area showed no significant differences between the patent and fused sutures. However, the width calcium value (width $\mathrm{Ca}, \mathrm{Wt} \%$ ), a measure of the statistical distribution of various calcium concentrations within the detected bone area, was significantly higher in the suture margins of patent sutures $(a: p \leq 0.05)$, demonstrating a more heterogeneous calcium distribution in these samples. In contrast, fused cases demonstrated more homogenous mineralisation in the bony plates of fused sutures due to a predominance of evenly mineralised osteons occupying the observed bone area.

\section{Energy dispersive $x$-ray microanalysis}

Elemental spectra obtained from microanalysis (Fig. 7a,b) at both the centres of sutural gaps and the tissue adjacent to sutural margins showed distinctive elemental peaks of carbon $(\mathrm{C})$, oxygen $(\mathrm{O})$, sodium $(\mathrm{Na})$, magnesium $(\mathrm{Mg})$, phosphorus $(\mathrm{P})$, chloride $(\mathrm{Cl})$, potassium $(\mathrm{K})$, sulphur $(\mathrm{S})$ and calcium $(\mathrm{Ca})$. In particular, the proportion of calcium (Ca) and sulphur (S) was significantly greater near the suture margins in comparison to the suture centres. This difference was evident in both the patent segments $(\mathrm{Ca}$ : $0.2 \pm 0.04 \mathrm{Wt} \%$ vs. $0.10 \pm 0.01 \mathrm{Wt} \% ; p \leq 0.005$ and $\mathrm{S}$ : $0.24 \pm 0.08 \mathrm{Wt} \%$ vs. $0.13 \pm 0.02 \mathrm{Wt} \% ; p \leq 0.05)$ and fused segments (Ca: $0.17 \pm 0.02 \mathrm{Wt} \%$ vs. $0.10 \pm 0.03 \mathrm{Wt} \%$; $p \leq 0.005$ and $\mathrm{S}: 0.16 \pm 0.01 \mathrm{Wt} \%$ vs. $0.09 \pm 0.03 \mathrm{Wt} \%$; $p \leq 0.05)$. Elemental composition did not differ between the analysed regions of patent $v s$. fused sutures.

\section{Polarised light microscopy}

Patent suture segments revealed a predominance of bright collagen fibres in the bone plates, which were perpendicular to each other without any specific lamellar organisation (Fig. 7c). This fibre pattern, together with the assessed cellular and structural histomorphometric indices, confirmed the presence of woven bone in patent segments. In contrast, polarised light microscopy demonstrated that fused segments had an increased number of osteons revealing a lamellar organisation of collagen fibrils (Fig. 7d).

\section{Analysis of the bone mineral density distribution}

Bone mineral density distribution measurements by quantitative backscattered electron imaging (qBEI) in synostotic cases revealed a significant difference in terms of the mineral distribution compared to patent sutures (Fig. $7 \mathrm{e}, \mathrm{f}, \mathrm{g}, \mathrm{h})$. The mean calcium content in the mineralised bone tissue area did not differ significantly between the patent and prematurely fused sutures (mean Ca: $18.09 \pm 1.5$ $\mathrm{Wt} \%$ vs. $17.34 \pm 1.88 ; p \geq 0.05$ ) (Fig. 7h). However, patent segments revealed a significant increase in mineralisation heterogeneity as reflected in the higher calcium width ( $\Delta$ width Ca: $8.59 \pm 0.32 \mathrm{Wt} \%$ vs. $7.30 \pm 0.75 \mathrm{Wt} \%$; $p \leq 0.05$ ) (Fig. 7h). While patent sutural margins showed dominant woven bone features and frayed mineralisation fronts (Fig. 7e,g - left upper image), the bony plates in prematurely fused sutures (Fig. 7f,g - right image) revealed the predominance of osteonal features (asterisks) - with thin cement lines (white arrows in right lower image), accompanied by smooth mineralised sutural outlines (Fig. $7 \mathrm{f}, \mathrm{g}$-right upper image), as observed in the backscattered electron images. However, the osteocyte lacunae present in the patent sutures were disorganised (Fig. $7 \mathrm{~g}$ - left image) and did not seem to be systematically connected to each other through canaliculi as in the fused cases.

\section{Discussion}

Bone growth at sutures encompasses a series of cellular activities: recruitment of mesenchymal cells to osteogenic cell lineage, stimulation of osteoblast proliferation and differentiation, as well as matrix mineralisation at the osteogenic front (Mao and Nah, 2004). However, progression of osteogenesis requires strict control at the advancing osteogenic fronts to preserve sutural disposition (Opperman, 2000; Mao and Nah, 2004). Skull growth and suture patency are based on simultaneous balanced increases in the synthesis of extracellular matrices of both fibrogenic and osteogenic cells; in this case, expansion of the fibrogenic component denies suture closure, while the expansion of the osteogenic cells and matrix increases the bone's size (Mao and Nah, 2004). In a competition between fibrogenic and osteogenic cells and/or factors (Mao and Nah, 2004), timely osteoblastic predominance is necessary to replace the fibrogenic component and to achieve timely suture closure essential for normal skull growth and development (De Pollack et al., 1996). Therefore, 
although in our assessment minor amounts of dense irregular connective tissue still appeared within clinically fused sutures, its diminished quantity in comparison to the control group of a corresponding age indicated that early osteoblastic predominance and/or fibroblast retreat led to premature clinically detectable suture fusion in infants.

In the fused suture segments, a quiescence phase of bone forming activity was observed from the less numerous and rather flat-shaped osteoblasts along with reduced osteoid seams (Miller et al., 1980; Nishino et al., 2001; Rosen, 2004; Amizuka et al., 2005). The observed differences in osteoblast number and shape between patent and fused sutural segments suggest that these two features are associated with different maturation stages in the course of suture development. Thus, nearly complete bone forming cycles were evident in prematurely fused sutures. In addition, the observed lower values of osteoid area per bone area in prematurely closed sutures are compatible with the findings on adult parietal bones with completed growth (Torres-Lagares et al., 2010). The observed shift to more osteoclastic activity in fused segments indicates an advanced stage of bone development where remodelling occurs to resorb woven bone in favour of the formation of secondary bone.

An increased osteocyte lacunar density assessed in the bony edges of patent sutures is in agreement with rare data on osteocyte number and morphology in woven bone (Hernandez et al., 2004). Woven bone osteocytes in an early phase of osteogenesis show shorter dendritic processes and do not express any particular alignment within the bone matrix. The osteocytes in woven bone are immature antecedents of lamellar bone osteocytes (Kusuzaki et al., 2000), which supports the observation that normal and prematurely closed sutures in agematched infants reflect two different stages of normal bone development. Nevertheless, owing to sutural bone maturation, fused sutures demonstrated a significantly lower number of osteocyte lacunae. However, the measured osteocyte lacunar number in prematurely fused sutures is still higher than in adult human parietal bone (TorresLagares et al., 2010). Thus, the decreasing osteocyte lacunar number with bone maturation may reflect a "timeline" of cranial bone maturation: (1) immature phase in patent sutures, (2) advanced maturation level in prematurely fused sutures, and (3) completely developed adult cranial bone. In addition, our study revealed larger osteocyte lacunae in the woven bone of patent suture margins. In this context, previous studies have shown that increased osteocyte lacunar size can be associated with a calcium deficiency of various aetiologies (Salomon, 1971; Bonucci and Gherardi, 1977; Sissons et al., 1984; Lane et al., 2006; Lane and Yao, 2010). Therefore, large lacunae might reflect a relative calcium deficiency due to a high demand for calcium during rapid formation of woven bone (Ardizzoni, 2001; Li et al., 2006; Mulder et al., 2008), in contrast to smaller lacunae found in the more mature bone of fused suture segments.

Previous studies reported locally enhanced boneforming activity in craniosynostosis. Increased parameters of osteoblastic cell differentiation indicated that elevated osteoblast maturation at the suture leads to premature ossification in non-syndromic craniosynostosis (De Pollack et al., 1996; Shevde et al., 2001). Cultured rabbit bone cells involved in craniosynostosis showed a pronounced response to recombinant human BMP-4 stimulation (Cooper et al., 2010), while human cells from patent sutures showed a weaker response to osteogenic stimuli (Coussens et al., 2009). In our study, EDXA in both patent and fused segments revealed slightly increased concentrations of calcium and phosphorus in the connective tissue near the suture margins (i.e., facing the mineralisation fronts) when compared to the centre of the suture gap. The simultaneous appearance of sulphur at these sites denotes the presence of matrix glycosaminoglycans, but also might suggest the presence of a moiety for attaining high local concentrations of calcium and phosphorus essential for the controlled local formation of calcium phosphate, as suggested by Arsenault and Ottensmeyer (1984). Backscattered electron analyses of the bone edges showed different mineralisation patterns in patent $v s$. fused sutures. A large part of the bone mineral is initially deposited quickly during the first days (Frost, 1963; Parfitt, 1987; Jee, 2001), and only a minor portion of the bone mineral is added slowly over months or years during the secondary mineralisation phase (Frost, 1963; Parfitt, 1987; Jee, 2001). This fact may explain our observation of similar calcium contents between the immature sutural bone and the more advanced bone in fused cases. Although woven bone areas have been reported to be more mineralised than the lamellar bone (Currey, 1998), our analyses at sutural edges may not have shown a significant result because of the existence of irregular low mineralised fronts in patent sutures and various mineralisation spots. However, we found that patent segments showed more mineralisation heterogeneity, which can be attributed to rapid bone formation and mineral deposition in woven bone (Rosen, 2004; Li et al., 2006; Mulder et al., 2008). In contrast, the fused segments demonstrated advanced modelling of the bony edges, which is reflected in the decreased calcium width. This homogeneous mineralisation profile in fused segments, together with the obtained histomorphometric data, demonstrates that with fusing, the woven bone is replaced by successive formation of secondary bone.

Despite the general expectation for similarities between suture growth and distraction osteogenesis/defect healing, our findings add new evidence that distraction osteogenesis might not be a reliable model for sutural growth and premature suture closure. Whereas in distraction gaps the tissue between the ends of the mineralised bone is first subject to bleeding, coagulation, granulation tissue and fibrosis (Kokich, 1976; Shapiro, 2008), bone directly develops at the suture edges in craniosynostosis. In addition, in contrast to the distraction gap (Yasui et al., 1997; Jazrawi et al., 1998; Sato et al., 1998; Ploder et al., 2002; Lafuente et al., 2009; Forriol et al., 2010), our analyses of sutural sites showed no verification of enchondral and transchondroid types of osteogenesis.

Our analyses at various analytical levels provide new insights into the cellular, architectural and compositional characteristics of normal (patent) vs. "pathological" (prematurely ossified) sutures. Namely, we have observed that the prematurely fused bony edges show a matured 
bone structure at all investigated levels. Hence, the developed pattern of lamellar bone points to an advanced stage in the sequence of normal bone development in contrast to the immature woven bone observed at the bony edges of the patent sutures. However, our findings raise additional questions that have not been addressed so far. For instance, considering the differences at all the investigated levels in craniosynostosis, it is not known whether the ossification process occurs early but with normal characteristics, or whether it might represent a pathological entity. As several metabolic and genetic bone diseases are known to be accompanied by pathological ossification processes (Elster et al., 1992; Koehler et al., 2003; Krimmel et al., 2004), some may be associated with secondary craniosynostosis (Koehler et al., 2003); however, there are no directly comparable studies on appropriate human skull bones. Based on the known characteristics of pathological ossification at other bone sites (e.g., osteoid characteristics, cellular characteristics, tissue organisation, mineralisation - Khurana, 2009), the structural and compositional features that we observed in prematurely fused sutures do not favour a true pathological or defective ossification process. Therefore, our data on non-syndromic prematurely fused sutures are in agreement with the theory of a normal ossification process that simply commences too early (Opperman, 2000). The timing of suture fusion and its underlying regulating signals seem to be the key points in craniosynostosis where premature fusion of cranial sutures may be understood as a normal fusion process that starts prematurely.

Several limitations of the study have to be taken into account. As this study has a cross-sectional design, an individuals' time course of osteogenesis and suture closure during growth is not directly assessable. Therefore, our study exclusively compares a control group and a craniosynostosis group of age-matched individuals. Although such study designs can be of particular interest in bone research when a longitudinal study cannot be done due to obvious ethical and practical constraints, the obtained data cannot compensate for demonstrating dynamic and temporal processes in craniosynostoses.

\section{Conclusions}

In conclusion, combined analyses at the cellular, material and structural levels of the sutures suggested that the bone segments in patent $v s$. fused sutures are associated with different stages in the course of normal osteogenesis process. Bony edges in fused suture segments showed various morphological features indicative of their more advanced stage in bone development/maturation, without any clues of a pathological or defective process of ossification. Therefore, our data support the theory of a normal ossification process in suture synostosis that simply commences too early. These findings may provide a basis for future strategies aiming to further understand craniosynostosis, predict suture fusion and determine the time point for surgical intervention.

\section{Disclosures}

The authors declare no conflict of interest.

\section{Acknowledgments}

The authors would like to thank the scientific editor, Prof. Dr. Hanns Plenk, for many detailed and very helpful comments. Moreover, we thank Marija Djuric and Brian Panganiban who provided helpful comments and research support on the manuscript. Petar Milovanovic thanks the Ministry of Science of Republic of Serbia, Pr.Nr: III45005. Björn Busse is a fellow of the DFG (Deutsche Forschungsgemeinschaft; BU 2562/1-1).

\section{References}

Alden TD, Lin KY, Jane JA (1999) Mechanisms of premature closure of cranial sutures. Childs Nerv Syst 15: 670-675.

Amizuka N, Li M, Nasu M, Maeda T, Shimomura J (2005) Histological evaluation for "bone quality" on two mouse models with different bone remodeling. J Bone Miner Metab 23: 43-47.

Ardizzoni A (2001) Osteocyte lacunar size-lamellar thickness relationships in human secondary osteons. Bone 28: 215-219.

Arsenault AL, Ottensmeyer FP (1984) Visualization of early intramembranous ossification by electron microscopic and spectroscopic imaging. J Cell Biol 98: 911-921.

Bloebaum RD, Holmes JL, Skedros JG (2005) Mineral content changes in bone associated with damage induced by the electron beam. Scanning 27: 240-248.

Bonucci E, Gherardi G (1977) Osteocyte ultrastructure in renal osteodystrophy. Virchows Arch A Pathol Anat Histopathol 373: 213-231.

Boyadjiev SA (2007) Genetic analysis of nonsyndromic craniosynostosis. Orthod Craniofac Res 10: 129-137.

Busse B, Hahn M, Soltau M, Zustin J, Püschel K, Duda GN, Amling M (2009) Increased calcium content and inhomogeneity of mineralization render bone toughness in osteoporosis: Mineralization, morphology and biomechanics of human single trabeculae. Bone 45: 1034-1043.

Busse B, Djonic D, Milovanovic P, Hahn M, Püschel K, Ritchie RO, Djuric M, Amling M (2010a) Decrease in the osteocyte lacunar density accompanied by hypermineralized lacunar occlusion reveals failure and delay of remodeling in aged human bone. Aging Cell 9: 1065-1075.

Busse B, Jobke B, Hahn M, Priemel M, Niecke M, Seitz S, Zustin J, Semler J, Amling M (2010b) Effects of strontium ranelate administration on bisphosphonatealtered hydroxyapatite: Matrix incorporation of strontium is accompanied by changes in mineralization and microstructure. Acta Biomater 6: 4513-4521. 
Chong SL, Mitchell R, Moursi AM, Winnard P, Losken HW, Bradley J, Ozerdem OR, Azari K, Acarturk O, Opperman LA, Siegel MI, Mooney MP (2003) Rescue of coronal suture fusion using transforming growth factor-beta 3 (TGF-beta 3 ) in rabbits with delayed-onset craniosynostosis. Anat Rec A Discov Mol Cell Evol Biol 274: 962-971.

Cohen MM Jr (1993) Sutural biology and the correlates of craniosynostosis. Am J Med Genet 47: 581-616.

Cooper GM, Lensie EL, Cray JJJ, DeCesare GE, Smalley MA, Losee JE, Mooney MP (2010) BMP-4 response in wild-type and craniosynostotic rabbit bone cells. Plast Reconstr Surg 125: 1403-1411.

Coussens AK, Hughes IP, Wilkinson CR, Morris CP, Anderson PJ, Powell BC, van Daal A (2008) Identification of genes differentially expressed by prematurely fused human sutures using a novel in vivo - in vitro approach. Differentiation 76: 531-545.

Coussens AK, Hughes IP, Morris CP, Powell BC, Anderson PJ (2009) In vitro differentiation of human calvarial suture derived cells with and without dexamethasone does not induce in vivo-like expression. J Cell Phys 218: 183-191.

Currey J (1998) Mechanical properties of vertebrate hard tissues. Proc Inst Mech Eng H J Eng Med 212: 399 411.

David DJ, Poswillo DE, Simpson DA (1982) The Craniosynostoses. Causes, Natural History, and Management. Springer, Berlin.

Davis C, Windh P, Lauritzen CG (2009) Spring-assisted cranioplasty alters the growth vectors of adjacent cranial sutures. Plast Reconstr Surg 123: 470-474.

De Pollack C, Renier D, Hott M, Marie PJ (1996) Increased bone formation and osteoblastic cell phenotype in premature cranial suture ossification (craniosynostosis). J Bone Miner Res 11: 401-407.

Elster AD, Theros EG, Key LL, Chen MY (1992) Cranial imaging in autosomal recessive osteopetrosis. Part II. Skull base and brain. Radiology 183: 137-144.

Enlow DH (1982) Handbook of Facial Growth. WB Saunders, Philadelphia.

Eswarakumar VP, Horowitz MC, Locklin R, MorrissKay GM, Lonai P (2004) A gain-of-function mutation of Fgfr2c demonstrates the roles of this receptor variant in osteogenesis. Proc Natl Acad Sci USA 101: 12555-12560.

Fehlow P (1993) Craniosynostosis as a risk factor. Childs Nerv Sys 9: 325-327.

Forriol F, Denaro L, Longo UG, Taira H, Maffulli N, Denaro V (2010) Bone lengthening osteogenesis, a combination of intramembranous and endochondral ossification: an experimental study in sheep. Strategies Trauma Limb Reconstr 5: 71-78.

Frost HM (1963) Bone Remodeling Dynamics. Thomas, Springfield, IL.

Gupta PC, Foster J, Crowe S, Papay FA, Luciano M, Traboulsi EI (2003) Ophthalmologic findings in patients with nonsyndromic plagiocephaly. J Craniofac Surg 14: 529-532.

Hahn M, Vogel M, Delling G (1991) Undecalcified preparation of bone tissue: report of technical experience and development of new methods. Virchows Arch A Pathol Anat Histopathol 418: 1-7.

Hernandez CJ, Majeska RJ, Schaffler MB (2004) Osteocyte density in woven bone. Bone 35: 1095-1099.

Hunenko O, Karmacharya J, Ong G, Kirschner RE (2001) Toward an understanding of nonsyndromic craniosynostosis: altered patterns of TGF-beta receptor and FGF receptor expression induced by intrauterine head constraint. Ann Plast Surg 46: 546-554.

Hunter AGW, Rudd NL (1976) Craniosynostosis. I. Sagittal synostosis; Its genetics and associated clinical findings in 214 patients who lacked involvement of the coronal suture(s). Teratol 14: 185-193.

Ignelzi MA, Jr., Wang W, Young AT (2003) Fibroblast growth factors lead to increased Msx2 expression and fusion in calvarial sutures. J Bone Miner Res 18: 751-759.

Jacob S, Wu C, Freeman TA, Koyama E, Kirschner RE (2007) Expression of Indian Hedgehog, BMP-4 and Noggin in craniosynostosis induced by fetal constraint. Ann Plast Surg 58: 215-221.

Jazrawi LM, Majeska RJ, Klein ML, Kagel E, Stromberg L, Einhorn TA (1998) Bone and cartilage formation in an experimental model of distraction osteogenesis. J Orthop Trauma 12: 111-116.

Jee WSS (2001) Integrated bone tissue physiology: Anatomy and physiology. In: Bone Mechanics Handbook (Cowin SC, ed), CRC Press, Boca Raton, FL, pp 1.1-1.68.

Kapp-Simon KA (1998) Mental development and learning disorders in children with single suture craniosynostosis. Cleft Palate Craniofac J 35: 197-203.

Kapp-Simon KA, Figueroa A, Jocher CA, Schafer M (1993) Longitudinal assessment of mental development in infants with nonsyndromic craniosynostosis with and without cranial release and reconstruction. Plast Reconstr Surg 92: 831-839.

Khurana J (2009) Bone pathology. Humana Press, Philadelphia.

Koehler A, Zimmer E-A, Freyschmidt J, Brossmann J, Wiens J, Sternberg A (2003) Koehler/Zimmer's Borderlands of Normal and Early Pathological Findings in Skeletal Radiography. Thieme, Stuttgart.

Kokich VG (1976) Age changes in the human frontozygomatic suture from 20 to 95 years. Am J Orthod 69: 411-430.

Kokich VG (1986) Biology of sutures. In: Craniosynostosis: Diagnosis, Evaluation, and Management (Cohen MMJ, ed), Raven, New York, pp 81-103.

Krimmel M, Niemann G, Will B, Reinert S (2004) Surgical correction of craniosynostosis in malignant osteopetrosis. J Craniofac Surg 15: 218-220.

Kusuzaki K, Kageyama N, Shinjo H, Takeshita H, Murata H, Hashiguchi S, Ashihara T, Hirasawa Y (2000) Development of bone canaliculi during bone repair. Bone 27: 655-659.

Kweldam CF, van der Vlugt JJ, van der Meulen JJNM (2010) The incidence of craniosynostosis in the Netherlands, 1997-2007. J Plast Reconstr Aesthet Surg 64: $583-588$.

Lafuente P, Franch J, Durall I, Manzanares C (2009) Experimental study of bone lengthening in dogs by means 
of backscattered scanning electron microscopy. Vet Surg 38: $388-397$.

Lane NE, Yao W, Balooch M, Nalla RK, Balooch G, Habelitz S, Kinney JH, Bonewald LF (2006) Glucocorticoid-treated mice have localized changes in trabecular bone material properties and osteocyte lacunar size that are not observed in placebo-treated or estrogendeficient mice. J Bone Miner Res 21: 466-476.

Lane NE, Yao W (2010) Glucocorticoid-induced bone fragility. Ann NY Acad Sci 1192: 81-83.

Lekovic GP, Bristol RE, Rekate HL (2004) Cognitive impact of craniosynostosis. Semin Pediatr Neurol 11: 305 310.

Li CY, Jepsen KJ, Majeska RJ, Zhang J, Ni R, Gelb BD, Schaffler MB (2006) Mice lacking cathepsin K maintain bone remodeling but develop bone fragility despite high bone mass. J Bone Miner Res 21: 865-875.

Magge SN, Westerveld M, Pruzinsky T, Persing JA (2002) Long-term neuropsychological effects of sagittal craniosynostosis on child development. J Craniofac Surg 13: 99-104.

Mao JJ, Nah H-D (2004) Growth and development: hereditary and mechanical modulations. Am J Orthod Dentofac Orthop 125: 676-689.

Mathijssen IM, van Splunder J, Vermeij-Keers C, Pieterman H, de Jong TH, Mooney MP, Vaandrager JM (1999) Tracing craniosynostosis to its developmental stage through bone center displacement. J Craniofac Genet Dev Biol 19: 57-63.

Miller SC, Bowman BM, Smith JM, Jee WSS (1980) Characterization of endosteal bone-lining cells from fatty marrow bone sites in adult beagles. Anat Rec 198: 163-173.

Moenning A, Jager R, Egert A, Kress W, Wardelmann E, Schorle H (2009) Sustained platelet-derived growth factor receptor alpha signaling in osteoblasts results in craniosynostosis by overactivating the phospholipase C-gamma pathway. Mol Cell Biol 29: 881-891.

Mooney MP, Burrows AM, Smith TD, Losken HW, Opperman LA, Dechant J, Kreithen AM, Kapucu R, Cooper GM, Ogle RC, Siegel MI (2001) Correction of coronal suture synostosis using suture and dura mater allografts in rabbits with familial craniosynostosis. Cleft Palate Craniofac J 38: 206-225.

Mooney MP, Losken HW, Moursi AM, Bradley J, Azari K, Acarturk TO, Cooper GM, Thompson B, Opperman LA, Siegel MI (2007) Anti-TGF-beta2 antibody therapy inhibits postoperative resynostosis in craniosynostotic rabbits. Plast Reconstr Surg 119: 1200-1215.

Mulder L, Koolstra JH, den Toonder JMJ, van Eijden TMGJ (2008) Relationship between tissue stiffness and degree of mineralization of developing trabecular bone. J Biomed Mater Res A 84A: 508-515.

Nishino I, Amizuka N, Ozawa H (2001) Histochemical examination of osteoblastic activity in op/op mice with or without injection of recombinant M-CSF. J Bone Miner Metab 19: 267-276.

Oppenheimer AJ, Rhee ST, Goldstein SA, Buchman SR (2009) Force-induced craniosynostosis in the murine sagittal suture. Plast Reconstr Surg 124: 1840-1848.
Opperman LA (2000) Cranial sutures as intramembranous bone growth sites. Dev Dyn 219: 472485.

Parfitt AM (1987) Bone remodeling and bone loss: Understanding the pathophysiology of osteoporosis. Clin Obstet Gynecol 30: 789-811.

Parfitt AM, Drezner MK, Glorieux FH, Kanis JA, Malluche H, Meunier PJ, Ott SM, Recker RR (1987) Bone histomorphometry: standardization of nomenclature, symbols, and units. Report of the ASBMR Histomorphometry Nomenclature Committee. J Bone Miner Res 2: 595-610.

Ploder O, Kanz F, Randl U, Mayr W, Voracek M, Plenk HJ (2002) Three-dimensional histomorphometric analysis of distraction osteogenesis using an implanted device for mandibular lengthening in sheep. Plast Reconstr Surg 110: 130-137.

Regelsberger J, Delling G, Helmke K, Tsokos M, Kammler G, Kränzlein H, Westphal M (2006) Ultrasound in the diagnosis of craniosynostosis. J Craniofac Surg 17: 623-625.

Regelsberger J, Schmidt T, Busse B, Herzen J, Tsokos M, Amling M, Beckmann F (2009) Synchrotronmicrocomputed tomography studies of normal and pathological cranial sutures: further insight. J Neurosurg Pediatr 5: 238-242.

Roschger P, Plenk H Jr, Klaushofer K, Eschberger J (1995) Anew scanning electron microscopy approach to the quantification of bone mineral distribution: backscattered electron image grey-levels correlated to calcium $\mathrm{K}$ alphaline intensities. Scanning Microsc 9: 75-87.

Roschger P, Fratzl P, Eschberger J, Klaushofer K (1998) Validation of quantitative backscattered electron imaging for the measurement of mineral density distribution in human bone biopsies. Bone 23: 319-326.

Roschger P, Paschalis EP, Fratzl P, Klaushofer K (2008) Bone mineralization density distribution in health and disease. Bone 42: 456-466.

Rosen CJ (2004) Anatomy, physiology and disease. In: The Physical Measurement of Bone (Langton CM, Njeh CF, eds), Institute of Physics Publishing, Bristol, pp 3-34.

Salomon CD (1971) Osteoporosis following calcium deficiency in rats. Calcif Tissue Int 8: 320-333.

Sato M, Yasui N, Nakase T, Kawahata H, Sugimoto M, Hirota S, Kitamura Y, Nomura S, Ochi T (1998) Expression of bone matrix proteins mRNA during distraction osteogenesis. J Bone Miner Res 13: 1221-1231.

Shapiro F (2008) Bone development and its relation to fracture repair. The role of mesenchymal osteoblasts and surface osteoblasts. Eur Cell Mater 15: 53-76.

Shen K, Krakora SM, Cunningham M, Singh M, Wang X, Hu FZ, Post JC, Ehrlich GD (2009) Medical treatment of craniosynostosis: recombinant Noggin inhibits coronal suture closure in the rat craniosynostosis model. Orthod Craniofac Res 12: 254-262.

Sherick DG, Buchman SR, Goulet RW, Goldstein SA (2000) A new technique for the quantitative analysis of cranial suture biology. Cleft Palate Craniofac J 37: 5-11.

Shevde NK, Bendixen AC, Maruyama M, Ling Li B, Billmire DA (2001) Enhanced activity of osteoblast 
differentiation factor (PEBP2 $\alpha \mathrm{A} 2 / \mathrm{CBFa} 1)$ in affected sutural osteoblasts from patients with nonsyndromic craniosynostosis. Cleft Palate Craniofac J 38: 606-614.

Shimoji T, Tomiyama N (2004) Mild trigonocephaly and intracranial pressure: report of 56 patients. Childs Nerv Syst 20: 749-756.

Shipster C, Hearst D, Somerville A, Stackhouse J, Hayward R, Wade A (2003) Speech, language, and cognitive development in children with isolated sagittal synostosis. Dev Med Child Neurol 45: 34-43.

Sissons H, Kelman G, Marotti G (1984) Mechanisms of bone resorption in calcium-deficient rats. Calcif Tissue Int 36: 711-721.

Skedros JG, Bloebaum RD, Bachus KN, Boyce TM, Constantz B (1993) Influence of mineral content and composition on graylevels in backscattered electron images of bone. J Biomed Mater Res 27: 57-64.

Slater BJ, Kwan MD, Gupta DM, Lee JK, Longaker MT (2009) The role of regional posterior frontal dura mater in the overlying suture morphology. Plast Reconstr Surg 123: 463-469.

Tholpady SS, Abdelaal MM, Dufresne CR, Gampper TJ, Lin KY, Jane JA, Sr., Morgan RF, Ogle RC (2004) Aberrant bony vasculature associated with activating fibroblast growth factor receptor mutations accompanying Crouzon syndrome. J Craniofac Surg 15: 431-438.

Thompson DNP, Harkness W, Jones B, Gonsalez S, Andar U, Hayward R (1995a) Subdural intracranial pressure monitoring in craniosynostosis: its role in surgical management. Childs Nerv Sys 11: 269-275.

Thompson DNP, Malcolm GP, Jones BM, Harkness WJ, Hayward RD (1995b) Intracranial pressure in single-suture craniosynostosis. Pediatr Neurosurg 22: 235-240.

Torres-Lagares D, Tulasne J-F, Pouget C, Llorens A, Saffar J-L, Lesclous P (2010) Structure and remodelling of the human parietal bone: An age and gender histomorphometric study. J Craniomaxillofac Surg 38: 325-330.

Van der Vlugt JJB, van der Meulen J, Creemers HE, Willemse SP, Lequin ML, Okkerse JME (2009) The risk of psychopathology in children with craniosynostosis. Plast Reconstr Surg 124: 2054-2060.

Vastardis H, Mulliken JB, Glowacki J (2004) Unilateral coronal synostosis: a histomorphometric study. Cleft Palate Craniofac J 41: 439-446.

Vedi S, Compston J (2003) Bone histomorphometry. In: Bone Research Protocols (Helfrich MH, Ralston $\mathrm{SH}$, eds), Humana Press, Totowa, NJ, pp 283-298.

Wilczak CA, Ousley SD (2009) Test of the relationship between sutural ossicles and cultural cranial deformation: results from Hawikuh, New Mexico. Am J Phys Anthropol 139: 483-493.

Yasui N, Sato M, Ochi T, Kimura T, Kawahata H, Kitamura Y, Nomura S (1997) Three modes of ossification during distraction osteogenesis in the rat. J Bone Joint Surg Br 79-B: 824-830.

\section{Discussion with Reviewers}

Reviewer I: The authors state that the relative size of osteocyte lacunae (lacuna area per bone area) is smaller in mature lamellar bone tissue than in newly forming woven bone. Is it known whether this is a result of increasing deposition of intercellular substance (fibres and matrix), of actual shrinkage of the lacunae or a combination of both processes?

Authors: Indeed, there are more osteocyte lacunae per bone area in woven bone and their size is also significantly greater. These observations are consistent with data obtained from other woven bone sites reported in the literature (Remaggi et al., 1998, additional reference; Hernandez et al., 2004, text reference). Hernandez et al. suggested that an increase in osteocyte cell size might be associated with the necessity for a rapid rate of matrix synthesis in woven bone (Hernandez et al., 2004, text reference). Evidently, former "surface" osteoblasts on lamellar bone become embedded between the layers of collagen fibrils with changing directions in the lamellae, and gradually reduce their extracellular matrix (ECM) production activity, as their content of organelles and cytoplasm is reduced. On the other hand, so-called "mesenchymal" osteoblasts (Shapiro, 2008, text reference) are much larger, may contain as many organelles as active surface osteoblasts, and are embedded in ECM with collagen fibrils/fibres with woven orientation. Therefore, wider peri-osteocyte spaces with signs of on-going ECM production (e.g., osteoid seams) can be observed in woven bone.

Reviewer I: Is it known whether the shape of osteoblastic cells, as described in this manuscript, is linked to proliferation activity and/or to stage of cell cycle of the osteoblasts?

Authors: The shape of the bone-forming cells that cover the bone surfaces varies from flat to cuboidal or low columnar. The cuboidal cell shape together with the characteristic appearance of the cell nuclei and organelles is consistent with metabolically active cells producing bone matrix. After completing their bone forming function, osteoblasts that do not undergo apoptosis or become entrapped in the bone matrix can transform to flat-shaped cells populating the bone surface of quiescent bone areas (bone-lining cells) (Khurana, 2009, text reference; Manolagas, 2000, additional reference).

Reviewer I: Is there any difference in the items analysed for this study between corticalis and diploe of the parietal bones?

Authors: We have found specific features in the pattern/ orientation of the bone trabeculae within the diploe. It seems that the mineralised bone trabeculae form according to the orientation of pre-existing mesenchymal tissue and collagen fibres, which is in line with the observations of Enlow (Enlow, 1982, text reference). However, it is difficult to comment on the definite differences between 
the compartments, as there is a rather smooth transition from the cortical bone to the diploe. We have added a high magnification image representing the observed orientation pattern in Fig. 4. A further study focusing on ground sections through the whole tissue block containing the suture gap with adjacent bone borders consecutively from the external periosteal surface to the intracranial surface covered by the internal periosteum under the dura mater may enable an additional assessment of cortical and diploic compartments in both investigated groups.

Reviewer II: The process of subsequent intramembranous bone formation in the sutures might be at least partly driven by the mechanical stimuli arising by the expanding brain. Are there similarities to distraction osteogenesis and could imbalances in the distraction process lead to advanced bone development?

Authors: The exact mechanism driving the suture's expansion and closure is not yet fully understood, but there are indeed some hypotheses that mechanical stimuli from the expanding brain contribute to suture growth (e.g., Davis et al., 2009, text reference; Oppenheimer et al., 2009, text reference). The premature suture closure, which occurs in craniosynostosis, would actually signify that there is a defect in the cross-talk between the brain and the bone. Therefore, the normal process of distraction osteogenesis might not represent the most reliable model for explaining the craniosynostotic phenotype. Another concern regarding a comparison with distraction osteogenesis is related to additional observed types of bone formation at the distraction gap (enchondral and transchondroid) (Dinu et al., 2011, additional reference; Forriol et al., 2010, text reference; Lafuente et al., 2009, text reference; Jazrawi et al., 1998, text reference; Fink et al., 2003, additional reference; Yasui et al., 1997, text reference; Lawler et al., 2010, additional reference; Ploder et al., 2002, text reference) as well as different sequences of osteogenesis (Shapiro, 2008, text reference). In addition, in distraction osteogenesis a "premature" closure of the distraction gap can also occur, either by starting distraction too late, or if the bone formation capacity is underestimated in setting the distraction parameters (Aronson and Harp, 1994, additional reference; Pereira et al., 2007, additional reference). Therefore, we think that distraction osteogenesis and premature suture closure indeed share several morphological features, but caution is required in terms of a mechanistic comparison of those entities.

Reviewer III: Can you say that fused sutures in cranial synostosis are similar to normal fused sutures? There is no evidence of normal fused sutures presented. There is also no timeline of events in either the normal or fused cases. It is therefore difficult to draw the conclusion that the sequence of events and structure for fused sutures is normal, just happens early.

Authors: We agree. In general, there is more data needed in regard to the various levels involved in cranial bones and suture characteristics. Moreover, hitherto comprehensive studies dealing with cellular, tissue and matrix characteristics that specifically focus on prematurely fused sutures are rare. As the here presented cell, tissue and matrix properties in prematurely fused cases do not bear clues of ossification processes that are pathological itself, we believe the present study indeed supports the theory that in cases with isolated craniosynostosis, ossification simply takes place early. However, the current study design certainly has limitations in terms of the progression of craniosynostosis because it does not follow the course of osteogenesis progressively but rather statically compares patent and fused segments at one specific time point.

Reviewer III: Recurrent deformity despite successful surgery is a common experience in the management of craniosynostosis, indicating a persisting abnormal osseous growth not amenable to treatment. Do the authors feel that this experience can be incorporated into their pathogenetic concept?

Authors: According to previous publications, we do confirm in our own series that the younger the patients are the more effective the surgical intervention is. This may underline the concept of an actually 'normal' suture fusion process that has started too early at one undetermined time point and spreads over the entire suture. However, this seems to be limited to the single suture synostosis most likely. Simple strip craniectomies have been shown to be successful in the very first weeks of sagittal and even coronal suture synostosis. Therefore, timing of the onset of suture fusion or timing of surgery is the crucial issue. Even early re-ossification can be seen in all cases, a tendency of recurrent deformities is not obvious in our series except in the more complex synostoses. In these, surgery is performed later at the age of 6-9 months. In summary, premature suture fusion is cured by timely surgery effectively as long as this process is limited to a single suture.

Reviewer III: Is it known whether biomechanical stimulation of these sutures in the evidence of craniosynostosis could have an effect on the balance between immigration of new mesenchymal stem cells and differentiation of those into new osteocytes? In other words, could wrong biomechanical stimuli lead to premature fusion besides growth factors and genetics?

Authors: We thank the referee for her/his important comment. Indeed, the relation between suture fusion and biomechanical stimuli has been subject of several studies (Review article: Kokich, 1986, text reference). In particular, experimentally tensile forces were frequently applied which led to increased deposition of bone which may be attributed to a differentiation of osteoblasts and osteocytes from mesenchymal stem cells at the sutural margins (Jackson et al., 1979; Guyman et al., 1980, additional references. In this connection, the expanding brain was commonly considered as a source of tension (Kokich, 1986, text reference; Oppenheimer et al., 2009, text reference), guiding sutural growth. In the case of craniosynostosis, the fact that the suture fuses prematurely might suggest either inappropriate biomechanical stimuli or rather a disordered cross-talk between the expanding brain and the suture. 


\section{Additional References}

Aronson J, Harp J (1994) Mechanical forces as predictors of healing during tibial lengthening by distraction osteogenesis. Clin Orthop Relat Res 301: 73-79.

Dinu C, Kretschmer W, Băciuţ M, Rotaru H, Bolboacă SD, Gheban D, Muste A, Cătoi C, Peştean C, Băciuţ G (2011) The effect of distraction rate on bone histological and histomorphometrical properties in an ovine mandible model. Rom J Morphol Embryol 52: 819-825.

Fink B, Pollnau C, Vogel M, Skripitz R, Enderle A (2003) Histomorphometry of distraction osteogenesis during experimental tibial lengthening. J Orthop Trauma 17: $113-118$

Guyman G, Kokich VG, Oswald R (1980) Ankylosed teeth as abutments for palatal expansion in the rhesus monkey. Am J Orthod 77: 486-499.

Jackson GW, Kokich VG, Shapiro PA (1979) Experimental and postexperimental response to anteriorly directed extraoral force in young Macaca nemestrina. Am J Orthod 76: 318-333.

Lawler ME, Tayebaty FT, Williams WB, Troulis MJ, Kaban LB (2010) Histomorphometric analysis of the porcine mandibular distraction wound. J Oral Maxillofac Surg 68: 1543-1554.

Manolagas SC (2000) Birth and death of bone cells: basic regulatory mechanisms and implications for the pathogenesis and treatment of osteoporosis. Endocr Rev. 21: 115-137.

Pereira MA, Luiz de Freitas PH, Da Rosa TF, Xavier CB (2007) Understanding distraction osteogenesis on the maxillofacial complex: a literature review. J Oral Maxillofac Surg 65: 2518-2523.

Remaggi F, Canè V, Palumbo C, Ferretti M (1998) Histomorphometric study on the osteocyte lacunocanalicular network in animals of different species. I. Woven-fibered and parallel-fibered bones. Ital J Anat Embryol 103: 145-155. 